\title{
Expression of functional inhibitory neurotransmitter transporters GlyT1, GAT-1, and GAT-3 by astrocytes of inferior colliculus and hippocampus
}

Elsa Ghirardini ${ }^{1,2,3}$, Simon L. Wadle ${ }^{1}$, Vanessa Augustin ${ }^{1}$, Jasmin Becker ${ }^{1}$, Sina Brill', Julia Hammerich¹, Gerald Seifert ${ }^{4}$ and Jonathan Stephan ${ }^{1 *}$ (D)

\begin{abstract}
Neuronal inhibition is mediated by glycine and/or GABA. Inferior colliculus (IC) neurons receive glycinergic and GABAergic inputs, whereas inhibition in hippocampus $(\mathrm{HC})$ predominantly relies on GABA. Astrocytes heterogeneously express neurotransmitter transporters and are expected to adapt to the local requirements regarding neurotransmitter homeostasis. Here we analyzed the expression of inhibitory neurotransmitter transporters in IC and $\mathrm{HC}$ astrocytes using whole-cell patch-clamp and single-cell reverse transcription-PCR. We show that most astrocytes in both regions expressed functional glycine transporters (GlyTs). Activation of these transporters resulted in an inward current (IGly) that was sensitive to the competitive GlyT1 agonist sarcosine. Astrocytes exhibited transcripts for GlyT1 but not for GlyT2. Glycine did not alter the membrane resistance $\left(R_{\mathrm{M}}\right)$ arguing for the absence of functional glycine receptors (GlyRs). Thus, IGly was mainly mediated by GlyT1. Similarly, we found expression of functional GABA transporters (GATs) in all IC astrocytes and about half of the HC astrocytes. These transporters mediated an inward current ( GABA $_{\text {GA }}$ that was sensitive to the competitive GAT-1 and GAT-3 antagonists NO711 and SNAP5114, respectively. Accordingly, transcripts for GAT-1 and GAT-3 were found but not for GAT-2 and BGT-1. Only in hippocampal astrocytes, GABA transiently reduced $R_{\mathrm{M}}$ demonstrating the presence of $G A B A_{A}$ receptors $\left(G A B A_{A} R s\right)$. However, I $I_{G A B A}$ was mainly not contaminated by $G A B A_{A} R$-mediated currents as $R_{M}$ changes vanished shortly after GABA application. In both regions, I IABA was stronger than $I_{\text {Gly }}$. Furthermore, in $\mathrm{HC}$ the $I_{G A B A} / I_{G l y}$ ratio was larger compared to IC. Taken together, our results demonstrate that astrocytes are heterogeneous across and within distinct brain areas. Furthermore, we could show that the capacity for glycine and GABA uptake varies between both brain regions.
\end{abstract}

Keywords: Inferior colliculus, Hippocampus, GlyT1, GAT-1, GAT-3

\section{Introduction}

Glycine and GABA mediate synaptic inhibition in matured circuits. Glycinergic and GABAergic inhibition are attributed predominantly to caudal and rostral brain regions, respectively. Nonetheless, both neurotransmitters coexist throughout the whole brain.

Mixed inhibitory synaptic transmission, with co-release of glycine and GABA from the same presynaptic terminal,

\footnotetext{
* Correspondence: jonathan.stephan@bio.uni-kl.de

${ }^{1}$ Animal Physiology Group, Department of Biology, University of Kaiserslautern, Erwin Schroedinger-Strasse 13, D-67663 Kaiserslautern, Germany

Full list of author information is available at the end of the article
}

takes place in various caudal brain regions, such as auditory brainstem, ventral respiratory group, cerebellum, and spinal cord [1-8]. In more rostral brain regions, like the hippocampus (HC), GABA is utilized for inhibitory synaptic transmission $[9,10]$, while glycine co-released from glutamatergic terminals can modulate NMDA receptor (NMDAR)-mediated signaling [11, 12]. Accordingly, glycine transporters (GlyTs) and GABA transporters (GATs) are widely expressed in astrocytes and neurons [13-16] to enable neurotransmitter clearance, reuptake, and modulation of neuronal signaling $[15,17,18]$. Astrocytes mainly express GlyT1 (Slc6A9), GAT-1 (Slc6A1), and/or GAT-3 (Slc6A11), which mediate an inward 
current and concomitant depolarization [19]. In addition, astrocytes can express ionotropic receptors for glycine (GlyRs) and GABA (GABA $\left.{ }_{\mathrm{A}} \mathrm{Rs}\right)$ [20-26].

In a previous study, we analyzed the expression of functional GlyTs and GATs in astrocytes in the lateral superior olive (LSO) - a conspicuous auditory brainstem center whose main inhibitory input is glycinergic after early postnatal development $[2,3]$. Astrocytes in this nucleus express functional GlyT1, GAT-1, and GAT-3 [19]. To study the region-dependent heterogeneity of GlyT and GAT expression in astrocytes, we chose two systems that contrast the LSO with respect to the utilization of glycine and GABA for inhibitory synaptic transmission: 1) The inferior colliculus (IC) residing in the midbrain belongs to the rostral part of the auditory brainstem and serves as a major hub for processing auditory cues $[4,27]$. Afferents from all auditory brainstem centers converge in the lateral lemniscal tract (LL) and project to the IC (Fig. 1a) $[4,8,28]$. The inhibitory part of the tract consists of glycinergic and GABAergic projections [8, 29-31]. Accordingly, IC astrocytes can be proposed to express GlyTs and GATs to account for neurotransmitter uptake. GlyT1 expression was found in the IC and attributed to glial cells [11, 13, 32]. Likewise, GAT-1 and GAT-3 are present in the IC [33, 34]. However, GlyTs and GATs in IC astrocytes have not yet been electrophysiologically characterized. 2) The $\mathrm{HC}$ is the second system of interest. Whereas its main circuitry is glutamatergic $[35,36]$, inhibitory synaptic transmission arises from GABAergic interneurons $[9,10]$. In line with this, astrocytes in the stratum radiatum express GAT-3, whereas GAT-1 has been attributed to interneurons [21, 37]. Glycine is co-released from glutamatergic terminals and modulates NMDAR-mediated signaling [11, 12]. For uptake of released glycine, GlyT1 is expressed in astrocytes and presynaptic terminals [11, 38-40]. However, functionality of GlyT1 in $\mathrm{HC}$ astrocytes has not been demonstrated prior to this study.

Here we analyzed the heterogeneity of expression and function of inhibitory neurotransmitter transporters in astrocytes from IC and HC. Using wholecell patch-clamp recordings from sulforhodamine 101 (SR101)-labeled astrocytes [19, 41, 42] and concomitant application of glycine or GABA to provoke transporter activation, together with single-cell reverse transcription (RT)-PCR, our results demonstrate that all IC astrocytes and about half of the HC astrocytes expressed functional GlyT1, GAT-1, and GAT-3. In contrast, GlyT2, GAT-2, and BGT-1 were never found. From our experiments, we can exclude that transporter currents were contaminated by respective ionotropic receptor-mediated currents. As expected, GAT activity was much stronger in $\mathrm{HC}$ astrocytes compared to IC astrocytes. Concurrently, our results show that IC and $\mathrm{HC}$ astrocytes exhibit heterogeneous properties, which reflect region-specific adaptation to local circuitry.

\section{Methods \\ Preparation of acute tissue slices and labeling of astrocytes}

We used tissue from C57BL/6 wild type mice of both genders at postnatal days 10-12 for our experiments. Mice were treated in accordance with the German law for conducting animal experiments and the NIH guidelines for the care and use of laboratory animals. Acute coronal slices were retrieved from midbrain and forebrain containing IC and $\mathrm{HC}$, respectively. After decapitation, the brain was quickly transferred into ice-cold cutting solution containing (in $\mathrm{mM}$ ): $26 \mathrm{NaHCO}_{3}, 1.25$ $\mathrm{NaH}_{2} \mathrm{PO}_{4}, 2.5 \mathrm{KCl}, 1 \mathrm{MgCl}_{2}, 2 \mathrm{CaCl}_{2}, 260$ D-glucose, 2 Na-pyruvate, and 3 myo-inositol, pH 7.4, bubbled with carbogen $\left(95 \% \mathrm{O}_{2}, 5 \% \mathrm{CO}_{2}\right) .270 \mu \mathrm{m}$ thick slices were cut using a vibratome (VT1200 S, Leica). Thereafter, slices were transferred to artificial cerebrospinal fluid (ACSF) containing (in $\mathrm{mM}$ ): $125 \mathrm{NaCl}, 25 \mathrm{NaHCO}_{3}$, $1.25 \mathrm{NaH}_{2} \mathrm{PO}_{4}, 2.5 \mathrm{KCl}, 1 \mathrm{MgCl}_{2}, 2 \mathrm{CaCl}_{2}, 10 \mathrm{D}$-glucose, 2 Na-pyruvate, 3 myo-inositol, and 0.44 ascorbic acid, $\mathrm{pH}$ 7.4, bubbled with carbogen. Slices were incubated for $30 \mathrm{~min}$ at $37{ }^{\circ} \mathrm{C}$ in $0.5-1 \mu \mathrm{M}$ SR101 and washed for another $30 \mathrm{~min}$ at $37{ }^{\circ} \mathrm{C}$ in SR101-free ACSF. This resulted in reliable labeling of astrocytes as shown before $[19,41]$. Thereafter, slices were kept at room temperature $\left(20-24{ }^{\circ} \mathrm{C}\right)$. All chemicals were purchased from Sigma-Aldrich or AppliChem, if not stated otherwise.

\section{Electrophysiology}

Whole-cell patch-clamp experiments were done as described before [19]. Briefly, the recording chamber was placed at an upright microscope equipped with infrared differential interference contrast (Eclipse FN1, Nikon, 60x water immersion objective, N.A. 1.0) and an infrared video camera (XC-ST70CE, Hamamatsu). Voltages and currents were recorded using a double patch-clamp EPC10 amplifier and PatchMaster software (HEKA Elektronik). The patch pipettes were pulled from borosilicate glass capillaries (GB150(F)-8P, Science Products) using a horizontal puller (P-87, Sutter Instruments). Pipettes had a resistance of 3-7 $\mathrm{M} \Omega$ using an intracellular solution containing (in $\mathrm{mM}$ ): 140 K-gluconate, 5 EGTA (glycol-bis(2-aminoethylether)$N, N^{\prime}, N^{\prime}, N^{\prime}$-tetraacetic acid), 10 Hepes (N-(2-hydroxyethyl)piperazine- $\mathrm{N}^{\prime}$-2-ethanesulfonic acid), $1 \mathrm{MgCl}_{2}, 2$ $\mathrm{Na}_{2} \mathrm{ATP}$, and $0.3 \mathrm{Na}_{2} \mathrm{GTP}, \mathrm{pH}$ 7.30. In some experiments the intracellular solution contained biocytin (0.3\%, Biomol) or alexa fluor (AF) $568(100 \mu \mathrm{M}$, Invitrogen) to allow the postfixational reconstruction of IC and $\mathrm{HC}$ neurons, respectively. Biocytin was labeled with NeutrAvidinhorseradish peroxidase conjugate (1:1000; Invitrogen) [43]. 
a

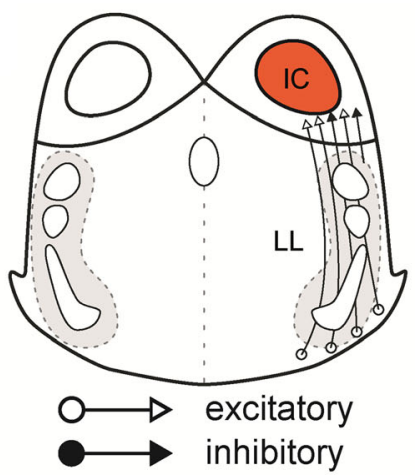

c $_{1}$ Non-passive astrocyte
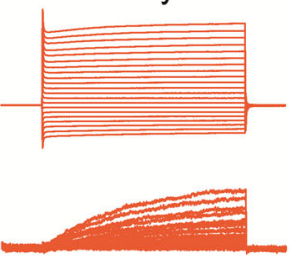

$100 \mathrm{pAL}$

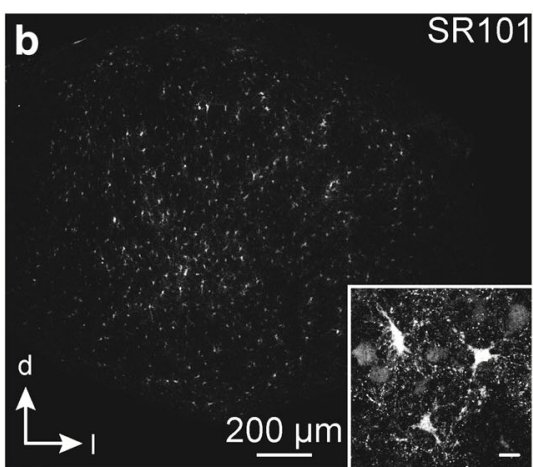

\section{C $_{2}$ Passive astrocyte}

$1 \mathrm{nA} \sqcup 5 \mathrm{nA}$

$10 \mathrm{~ms}$
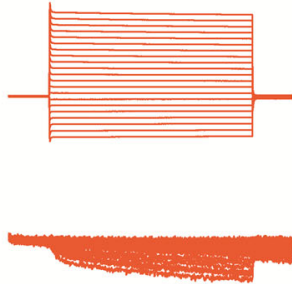

d

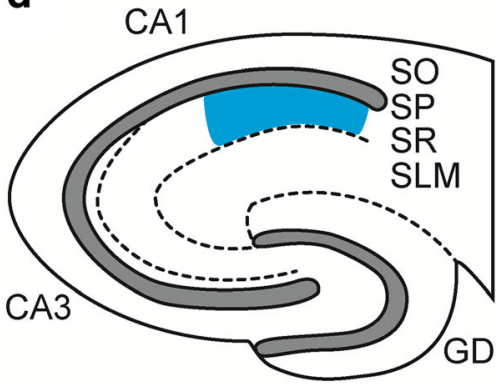

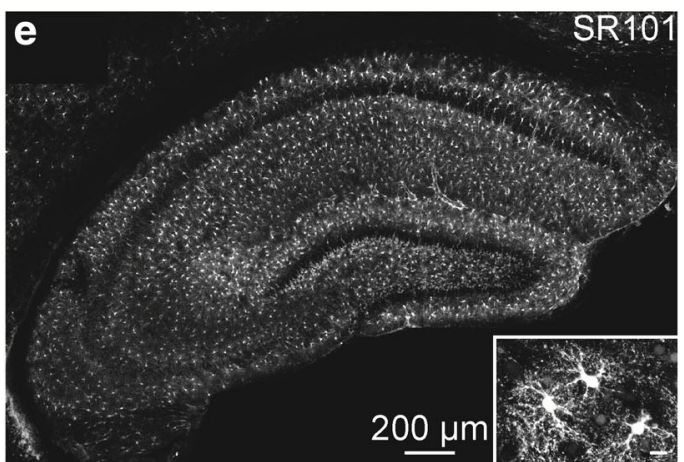

$f_{1}$ Non-passive

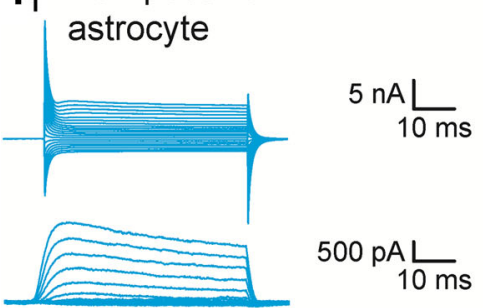

$f_{2}$ Passive

astrocyte
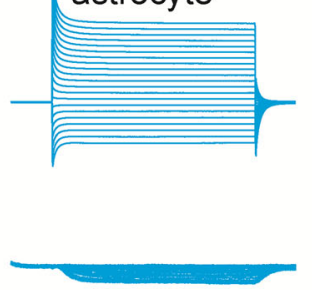

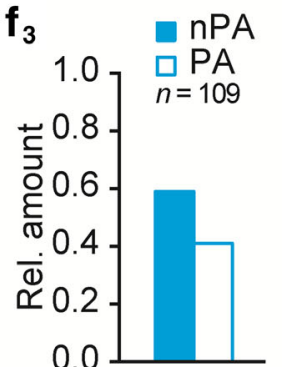

Fig. 1 Identification of IC and HC astrocytes. a, d: Semischematic drawings of coronal sections containing the central nucleus of the IC together with the lateral lemniscal tract (LL) (A) and the CA1 region of the HC (CA: cornu ammonis; GD: gyrus dentatus; SO: stratum oriens; SP: stratum pyramidale; SR: stratum radiatum; SLM: stratum lacunosum moleculare). b, e: SR101-labeled cells (astrocytes) were widely distributed within the IC (b) and the HC (e). They exhibited a small soma and were highly branched (insets in b and e; scale bar: $10 \mu \mathrm{m}$ ). $\mathbf{c}$, f: Astrocytes were clamped to $E_{H}=-85 \mathrm{mV}$ and were stepwise hyper- and depolarized from $-150 \mathrm{mV}$ to $+50 \mathrm{mV}$, with $10 \mathrm{mV}$ increments. Membrane currents were recorded (top) and leak currents were subtracted ( $\mathrm{p} / 4$; bottom). Non-passive astrocytes (nPA) expressed time- and voltage-dependent outward currents $\left(c_{1}, f_{1}\right)$, whereas passive astrocytes (PA) lacked these currents $\left(c_{2}, f_{2}\right)$. About $2 / 3$ of $I C$ astrocytes were passive $\left(c_{3}\right)$, whereas it was the opposite in the $\mathrm{HC}\left(\mathrm{f}_{3}\right) . n$ represents the number of recorded cells 
Astrocytes and neurons in the central nucleus of the IC (Fig. 1a; Additional file 1: Figure $\mathrm{S} 1 A_{1}$ ) and CA1 region of the $\mathrm{HC}$ (Fig. 1d; Additional file 1: Figure $\mathrm{S} 1 A_{2}$ ) were clamped to a holding potential $\left(E_{\mathrm{H}}\right)$ of $-85 \mathrm{mV}$ and $-70 \mathrm{mV}$, respectively. The cells were hyper- and depolarized using a standard step protocol ranging from -150 to $+50 \mathrm{mV}$ with $10 \mathrm{mV}$ increments. The resulting current traces were sampled at $50 \mathrm{kHz}$. We performed a standard leak subtraction protocol $(\mathrm{p} / 4)$ to isolate currents mediated by voltage-activated channels. Four step protocols were executed repetitively that comprised a reduced step size of $25 \%$. Thereafter, the recorded current traces were add together and subtracted from the initial recording (Fig. 1 $\mathrm{c}_{1-2}, \mathrm{f}_{1-2}$, Additional file 1: Figure S1B).

Glycine and GABA, both $1 \mathrm{mM}$ in ACSF, were applied in two ways: 1) In experiments analyzing the maximal neurotransmitter-induced current and depolarization (Figs. 2 and 4) both transmitters were administered using a peristaltic pump (Reglo, Ismatec) at a rate of $1-2 \mathrm{ml} / \mathrm{min}$. Data were sampled at $100 \mathrm{~Hz}$. We monitored putative changes of membrane resistance $\left(R_{\mathrm{M}}\right)$ and series resistance $\left(R_{\mathrm{S}}\right)$ every $30 \mathrm{~s}(\hat{=} 0.033 \mathrm{~Hz})$ using hyperpolarizing test pulses $(\Delta U=5 \mathrm{mV})$ [44]. The resulting currents were sampled at $20 \mathrm{kHz}$. 2) When pharmacologically isolating transporters mediating membrane currents (Figs. $3 \mathrm{a}$ and $5 \mathrm{a}$ ) neurotransmitters were applied via focal pressure injection (PDES-2 T, NPI; 12 psi). Therefore, a pipette with a resistance of 3-7 $\mathrm{M} \Omega$ was filled with glycine or GABA and positioned approximately $20 \mu \mathrm{m}$ apart from the recorded cell [19]. Membrane currents were sampled at $1 \mathrm{kHz}$. In order to detect additionally shortlasting receptor-mediated changes in membrane conductance during focal application of neurotransmitters (Figs. 3c and 5c, Additional file 2: Figure S2B-E), hyperpolarizing test pulses were applied at $1 \mathrm{~Hz}$ (Additional file 2: Figure $\mathrm{S} 2 A$ ) and $R_{\mathrm{M}}$ of astrocytes and neurons was calculated [44]. All recordings were low-pass filtered at $2.9 \mathrm{kHz}$. Data were processed and analyzed using "IGOR Pro 6.2" software (Wavemetrics). Measurements were rejected if $R_{\mathrm{S}}$ exceeded $15 \mathrm{M} \Omega$.

\section{Single-cell RT-PCR}

The patch pipette was filled with $3 \mu$ of intracellular solution. Next, astrocytes were patch-clamped as described in the preceding paragraph. After determination of the $I-V$ relationship, the cytoplasm was sucked into the patch pipette, which was then retracted from the slice. The remaining cell parts were sucked into the patch pipette and the intracellular solution containing the cytoplasm was put into a $50 \mu \mathrm{l}$ PCR reaction tube containing

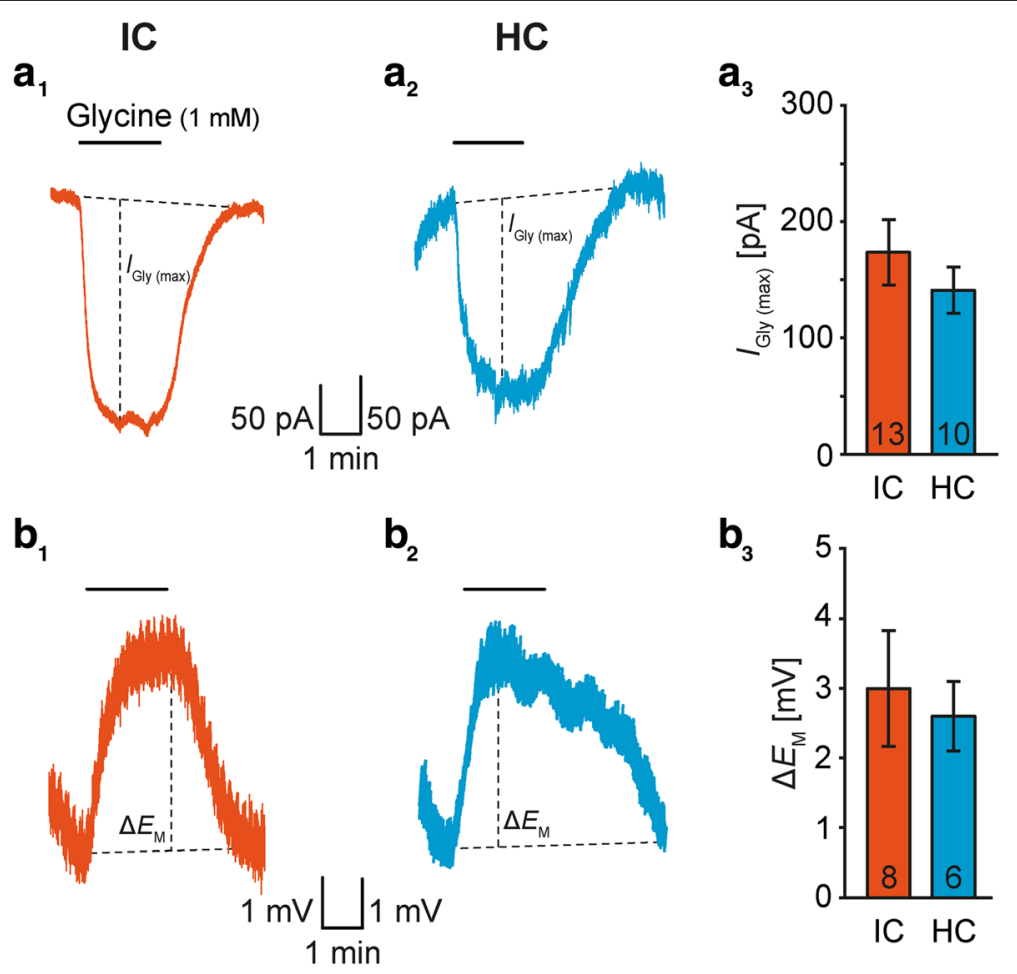

Fig. 2 Glycine-induced transients in IC and HC astrocytes. a-b: Application of glycine (1 mM) caused an inward current $\left(I_{G l y}(\max ) ; E_{H}=-85 \mathrm{mV} ; a_{1-2}\right)$ and a membrane depolarization $\left(\Delta E_{M} ; b_{1-2}\right)$, which was not different between IC and $\mathrm{HC}$ astrocytes $\left(\mathrm{a}_{3}, \mathrm{~b}_{3}\right)$. The number of recorded cells $(n)$ is given within the diagrams. Shown are mean values \pm SEM. Significance levels in panels $a_{3}$ and $b_{3}$ were Šidák corrected for two comparisons (see Methods section) 

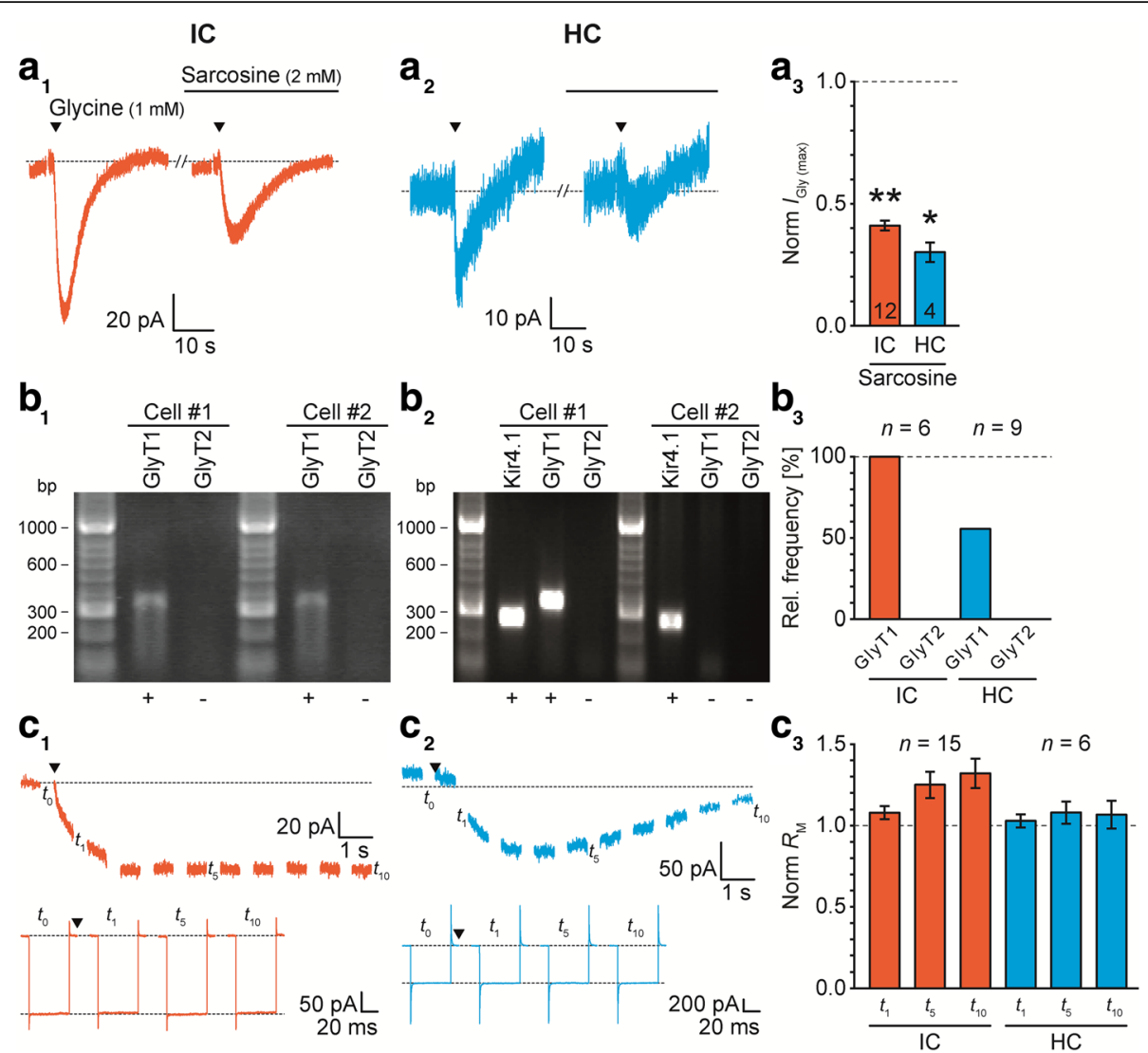

Fig. $3 \mathrm{IC}$ and HC astrocytes express GlyT1. a: Focal application of glycine ( $1 \mathrm{mM}, 0.5 \mathrm{~s}$; triangles) elicited an $I_{\mathrm{Gly}}\left(E_{\mathrm{H}}=-85 \mathrm{mV} ; \mathrm{a}_{1-2}\right)$. The competitive GlyT1 agonist sarcosine $(2 \mathrm{mM})$ reduced $I_{G l y ~}(\max )\left(\mathrm{a}_{3}\right)$. b: Single-cell RT-PCR revealed transcripts for GlyT1 in all IC astrocytes and about half of the HC astrocytes. Transcripts for GlyT2 were not found. c: Focal application of glycine (1 mM, 10 s; triangle) induced a long lasting inward current $\left(E_{\mathrm{H}}=-85 \mathrm{mV} ; \mathrm{c}_{1-2}\right.$, top). Responses to test pulse (see Additional file 2: Figure $\mathrm{S} 2 \mathrm{~A}$ ) were used to calculate $R_{\mathrm{M}}$ at $t_{0}, t_{1}, t_{5}$, and $t_{10}$ ( $c_{1-2}$, bottom). Upon glycine application, $R_{M}$ was not reduced in $\mathrm{IC}$ and $\mathrm{HC}$ astrocytes $\left(\mathrm{C}_{3}\right)$. The number of recorded cells $(n)$ is given within the diagrams. Shown are mean values \pm SEM. Significance levels in $c_{3}$ were Šidák corrected for three comparisons (see Methods section). bp: base pairs

$3 \mu \mathrm{l}$ of diethyl pyrocarbonate $(0.1 \%)$-treated water (ThermoFisher Scientific). To avoid degradation by RNAse activity the sample was immediately frozen in liquid nitrogen and stored at $-80{ }^{\circ} \mathrm{C}$. Samples were rejected, if the patch was unstable during cell extraction or fragments from neighboring cells stuck at the pipette.

For transcription of mRNA into cDNA reverse transcriptase (SuperScript III, 100 U; ThermoFisher Scientific), RNAse inhibitor (RNAseOUT, $40 \mathrm{U}$; ThermoFisher Scientific), random hexamers $(50 \mu \mathrm{M}$, ThermoFisher Scientific), first-strand buffer (ThermoFisher Scientific), and dithiothreitol (DTT; $10 \mathrm{mM}$; ThermoFisher Scientific) were added to the frozen sample (total volume: $13 \mu \mathrm{l})$. Next, RT was performed for $1 \mathrm{~h}$ at $37^{\circ} \mathrm{C}$. Subsequently, a multiplex PCR was performed to identify transcripts of inhibitory neurotransmitter transporters. MPprimer software [45] was used to create primer sequences (Table 1). Primers were chosen to be located on different exons. Thus, amplification of DNA, which contains exons and introns, would result in larger product length compared to the amplicon of spliced mRNA that could be distinguished after gel electrophoresis. The PCR reaction mix contained: $5 \times$ PCR buffer including dNTPs $(50 \mu \mathrm{M}$; Bioline), Taq Polymerase (4 U, Bioline), $200 \mathrm{nM}$ primers (Eurofins Scientific), $10 \mu \mathrm{l}$ of the RT reaction product, $\mathrm{H}_{2} \mathrm{O}$ (ad $50 \mu \mathrm{l}$, Ampuwa, Fresenius Kabi). Fifty PCR cycles were performed: denaturation for $25 \mathrm{~s}$ at $94{ }^{\circ} \mathrm{C}$, annealing for $2 \mathrm{~min}$ (first 5 cycles) and $45 \mathrm{~s}$ (subsequent 45 cycles) at $51{ }^{\circ} \mathrm{C}$, and elongation for $25 \mathrm{~s}$ at $72{ }^{\circ} \mathrm{C}$. Afterwards, a second PCR with nested primers and 40 cycles was conducted: denaturation for $25 \mathrm{~s}$ at $94{ }^{\circ} \mathrm{C}$, annealing for $2 \mathrm{~min}$ (first 5 cycles) and $45 \mathrm{~s}$ (subsequent 35 cycles) at $54{ }^{\circ} \mathrm{C}$, and elongation for $25 \mathrm{~s}$ at $72{ }^{\circ} \mathrm{C}$. The second PCR reaction mix contained Platinum Taq Polymerase $(1 \mathrm{U}$, ThermoFisher Scientific), $10 \times$ PCR buffer $\left(\mathrm{MgCl}_{2}\right.$-free; ThermoFisher Scientific), $2.5 \mathrm{mM} \quad \mathrm{MgCl}_{2}$ (ThermoFisher Scientific), $50 \mu \mathrm{M}$ dNTPs (Bioline), nested primers (200 nM, Eurofins Scientific), and $2 \mu \mathrm{l}$ of the first PCR reaction product. 
Table 1 Primers for single-cell RT-PCR

\begin{tabular}{|c|c|c|c|}
\hline Gene & Sequence & Expected amplicon size [bp] & GeneBank accession number \\
\hline$\overline{\text { GlyT1 }}$ & $\begin{array}{l}\text { fwd 5'-CACCAACTGTGCTACCAGCGTCTA-3' } \\
\text { rev 5'-GCATAGTTGTCCATCAGCAGCAGC-3' }\end{array}$ & 390 & NM_008135.4 \\
\hline GlyT1 (nested) & $\begin{array}{l}\text { fwd 5'-GCTTCGTCATCTTCTCCATCCTG-3' } \\
\text { rev 5'-CAGTAGATGCCTGCCTGGCTG-3' }\end{array}$ & 337 & \\
\hline GlyT2 & $\begin{array}{l}\text { fwd 5'-TCCTGTGTTATCGGTGACCATCC-3' } \\
\text { rev 5'-GAGTGGCCGCATCCTTCCATA-3' }\end{array}$ & 430 & NM_148931.3 \\
\hline GlyT2 (nested) & $\begin{array}{l}\text { fwd 5'-TCTGCATGACTGCCTATCCGAACT-3' } \\
\text { rev 5'-TGTGATGAAGTACCAGATGCCGG-3' }\end{array}$ & 329 & \\
\hline GAT-1 & $\begin{array}{l}\text { fwd 5'-GATGACAGATGGACTGGACAAG-3' } \\
\text { rev 5'-CACGATGGAGAAGATGACGAAT-3' }\end{array}$ & 430 & NM_178703.4 \\
\hline GAT-1 (nested) & $\begin{array}{l}\text { fwd 5'-TTGGACTGGAAAGGTGGTCTA-3' } \\
\text { rev 5'-ACGATGGAGAAGATGACGAATC-3' }\end{array}$ & 324 & \\
\hline GAT-2 & $\begin{array}{l}\text { fwd 5'-TTATTGTGTCCGTCATCTCGTT-3' } \\
\text { rev 5'-ACTTCTTGTTGTAGGTCAGTGG-3' }\end{array}$ & 309 & NM_144512.2 \\
\hline GAT-2 (nested) & $\begin{array}{l}\text { fwd 5'-GTTCTTCATCGGGCTCATCAT-3' } \\
\text { rev 5'-TAGGTCAGTGGCGTGTATTTG-3' }\end{array}$ & 279 & \\
\hline GAT-3 & $\begin{array}{l}\text { fwd 5'-GGGCATCTTCATCTTCTTCTG-3' } \\
\text { rev 5'-GGTTCAGGATTCATTTACACGC-3' }\end{array}$ & 390 & NM_172890.3 \\
\hline GAT-3 (nested) & $\begin{array}{l}\text { fwd 5'-GGGCATCTTCATCTTCTITCTG-3' } \\
\text { rev 5'-AGTGTGTCTCCTTCTCTGTGAT-3' }\end{array}$ & 320 & \\
\hline BGT-1 & $\begin{array}{l}\text { fwd 5'-ACTTTCTTCTTCTCCTTGAGCA-3' } \\
\text { rev 5'-CTCTGGCACTTCCTACAAATGA-3' }\end{array}$ & 324 & NM_133661.3 \\
\hline BGT-1 (nested) & $\begin{array}{l}\text { fwd 5'-ACTTCTTCTTCTCCTTGAGCA-3' } \\
\text { rev 5'-ATGAGTTCTTGTTTGGCTGGA-3' }\end{array}$ & 284 & \\
\hline Kir4.1 & $\begin{array}{l}\text { fwd 5'-ACT TTC TTC TTC TCC TTG AGCA-3' } \\
\text { rev 5'-CTC TGG CAC TTC CTA CAA ATGA-3' }\end{array}$ & 324 & NM_001039484.1 \\
\hline Kir4.1 (nested) & $\begin{array}{l}\text { fwd 5'-ACT TTC TTC TTC TCC TTG AGCA-3' } \\
\text { rev 5'-ATG AGT TCT TGT TTG GCT GGA-3' }\end{array}$ & 284 & \\
\hline
\end{tabular}

fwd Forward (/sence) primer, rev Reverse (/antisence) primer, bp Base pairs

Positive controls were performed with mRNA extracted from mouse brainstem by using an mRNA extraction kit (Dynabeads mRNA Purification Kit, Invitrogen; Additional file 3: Figure S3). For negative controls, the patch pipette was positioned close to the tissue in the recording chamber and ACSF was sucked into the pipette. Subsequently, the probe was frozen in liquid nitrogen and used for RT-PCR (Additional file 3: Figure S3). All amplified PCR products were loaded on an agarose gel (1.5\%), labeled with $1 \%$ ethidium bromide (Carl Roth), and analyzed using a transilluminator (Biometra TI 1). To determine the PCR product length we used a standard DNA ladder (HyperLadder 50 bp, Bioline).

Initial experiments showed that some $\mathrm{HC}$ astrocytes were devoid of any target RNA (GlyTs or GATs). To prove successful RNA extraction from HC astrocytes transcripts for the inwardly rectifying $\mathrm{K}^{+}(\mathrm{Kir})$ channel 4.1 were detected, which are present in all $\mathrm{HC}$ astrocytes [46].

\section{Confocal microscopy}

The labeling with SR101 - used for a priori identification of IC and HC astrocytes - and AF568 was documented as described before [41] using a confocal microscope
(Leica TCS SP5 LSM: HC PL FLUOTAR $10 \times 0.30$ DRY; HCX PL APO Lambda blue $63 \times 1.4$ OIL UV) and LAS AF software. Fluorophores were detected as follows (excitation wavelength/filtered emission wavelength): SR101 (SP5: $561 \mathrm{~nm} / 580-620 \mathrm{~nm}$ ) and AF568 (561 nm/580$620 \mathrm{~nm})$. To improve the quality of confocal micrographs and reduce background fluorescence, we used a Kalman filter (averaging of four identical image sections). Images were processed using Fiji software [47].

\section{Statistics}

Results were statistically analyzed using WinSTAT (R. Fitch Software). Data were tested for normal distribution with Kolmogorov-Smirnov test. In case of normal distribution, results were assessed by one-tailed, paired or non-paired Student's $t$-tests. In the absence of a normal distribution, results were assessed by Wilcoxon test for paired or U-test (Mann-Whitney) for non-paired data. $P$ represents the error probability, ${ }^{*} P<0.05,{ }^{* *} P<0.01,{ }^{* * *} P<0.001 ; n$ represents the number of experiments or cells/slices/animals. In case of multiple comparisons data were statistically analyzed by the tests described above under post hoc Šidák correction of critical values [48]: two comparisons: Fig. $2 \mathrm{a}_{3}$, 
Fig. $4 \mathrm{a}_{3}$, Table 2 ; ${ }^{*} P<0.025,{ }^{* *} P<0.005$, ${ }^{* * *} P<0.0005$; three comparisons: Fig. $2 c_{3}$, Fig. $4 c_{3}$, Additional file 2: Figure $\mathrm{S} 2 B_{3}-E_{3}$, Table $3 ;{ }^{*} P<0.017,{ }^{* *} P<0.0033$, *** $P<0.0003$. Data are provided as mean \pm SEM.

\section{Results}

\section{Identification of IC and HC astrocytes}

SR101 labeling is used in many different brain regions to identify astrocytes in acute tissue slices [19, 41, 42]. We mentioned before that incubation of acute slices with SR101 results in labeling of putative astrocytes in the IC, but we did not electrophysiologically confirm the identity of these SR $101^{+}$cells [19]. In IC and HC (CA1, stratum radiatum), SR101-labeled cells comprised a small sized soma with several branching processes. In $\mathrm{HC}$, these cells exhibited strong branching, whereas in IC they appeared to be less complex (Fig. 1b, e). The SR101-labeled cells exhibited membrane properties of classical astrocytes, i.e. a highly negative membrane potential $\left(E_{\mathrm{M}}\right.$ : IC: $-84.2 \pm$ $0.3 \mathrm{mV}, n=207 / 116 / 101$; HC: $-81.8 \pm 0.4 \mathrm{mV}, n=109 / 83 /$ 36) and a low $R_{\mathrm{M}}$ (IC: $8.3 \pm 0.7 \mathrm{M} \Omega, n=207 / 116 / 101$; HC: $9.7 \pm 0.6 \mathrm{M} \Omega, n=109 / 83 / 36)$. Due to the presence of voltage-activated outward currents, non-passive and passive astrocytes were identified (IC: $28 \% / 72 \%, n=207 / 116 /$
101, HC: $59 \% / 41 \%, n=109 / 83 / 36$, Fig. 1c, f), which is typical for that developmental stage.

\section{GlyT expression in IC and HC astrocytes}

Astrocytes in many brain regions express GlyTs [15], whereas GlyRs are only rarely present $[20,22]$. To analyze the expression of functional GlyTs in IC and $\mathrm{HC}$ astrocytes, we first characterized the response of membrane current and potential upon glycine bath application. The wash-in caused a reversible glycine-induced inward current $\left(I_{\mathrm{Gly}}\right)$ that usually peaked within the first minute ( $I_{\mathrm{Gly}(\max )}$ : IC: $173 \pm 28 \mathrm{pA}, n=13 / 11 / 10 ; \mathrm{HC}: 141 \pm 20 \mathrm{pA}$, $n=10 / 9 / 6 ; P=0.200$; Fig. $2 \mathrm{a})$. Upon prolonged glycine administration, $I_{\text {Gly }}$ partially recovered to a newly formed steady-state level in some recordings. Similarly, glycine induced a reversible depolarization $\left(\Delta E_{\mathrm{M} \text { (Gly) }}\right.$ IC: $3.0 \pm$ $0.8 \mathrm{mV}, n=8 / 8 / 7$; HC: $2.6 \pm 0.5 \mathrm{mV}, n=6 / 6 / 5 ; P=0.375$; Fig. $2 \mathrm{~b}$ ). To prove whether $I_{\mathrm{Gly}}$ and $\Delta E_{\mathrm{M} \text { (Gly) }}$ are mediated by GlyT1, we focally applied glycine in the absence and presence of sarcosine (Fig. $3 \mathrm{a}_{1-2}$ ). The competitive GlyT1 agonist itself caused an inward current by activation of the transporter and subsequently competed with applied glycine [19]. Sarcosine reduced $I_{\text {Gly (max) }}$ by about $60-70 \%$ (IC: $59 \pm 2 \%, n=12 / 5 / 5, P<0.001$; HC: $70 \pm 4 \%, n=4 / 4 / 2$,

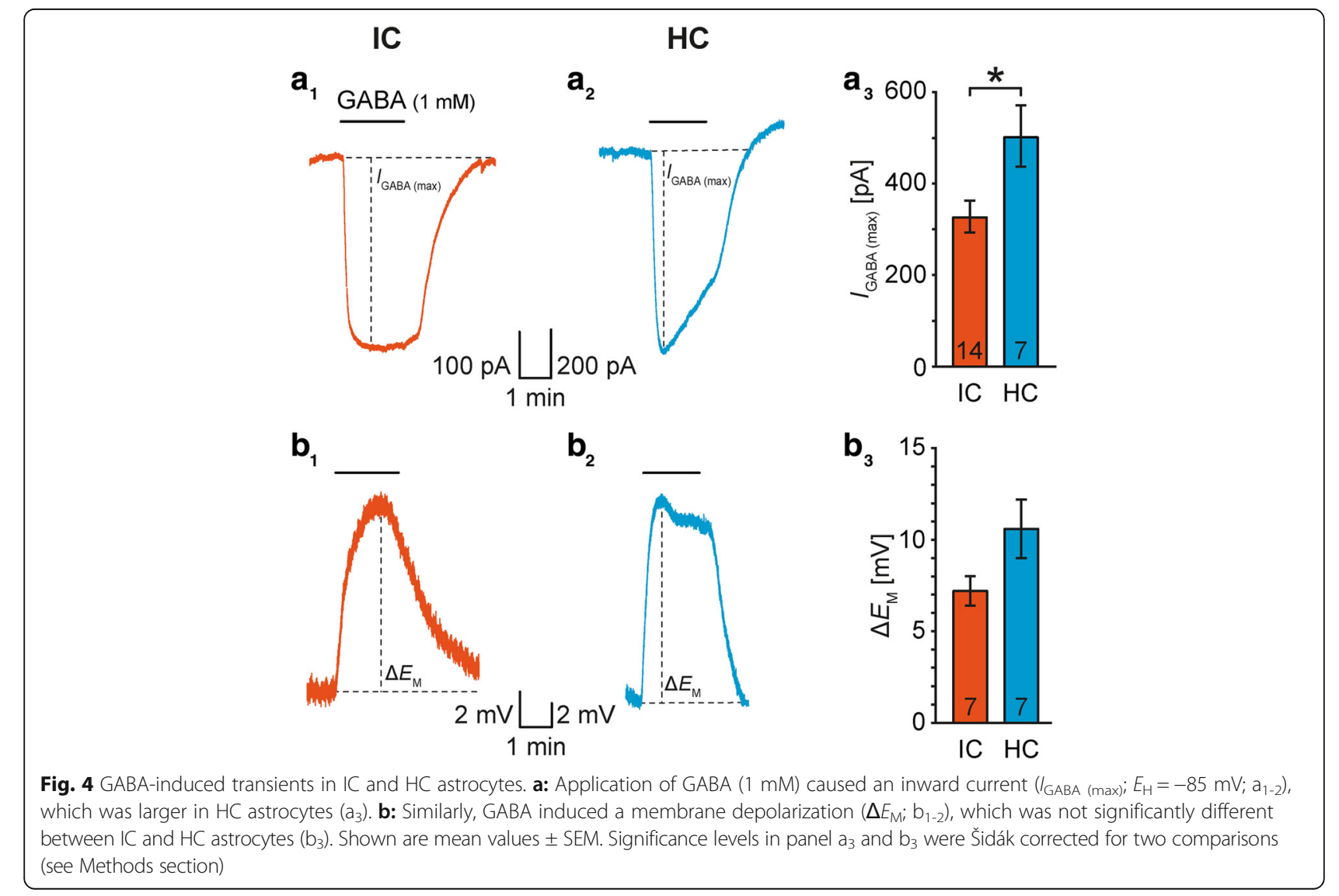


Table 2 Glycine- and GABA-induced inward current and depolarization in IC and HC astrocytes

\begin{tabular}{|c|c|c|c|c|c|c|c|c|c|c|c|c|}
\hline Region & $I_{\text {Gly (max) }}[p A]$ & $P$ & $I_{\text {GABA (max) }}[p A]$ & $P$ & Ratio & $P$ & $\Delta E_{M(G l y)}[\mathrm{mV}]$ & $P$ & $\Delta E_{M(G A B A)}[m V]$ & $P$ & Ratio & $P$ \\
\hline$\overline{I C}$ & $173 \pm 28(13)$ & & $327 \pm 35(14)$ & & 1.9 & 0.002 & $3.0 \pm 0.8(8)$ & & $7.2 \pm 0.8(7)$ & & 2.4 & 0.003 \\
\hline & & 0.200 & & 0.009 & & ${ }^{* *} \mathrm{SC}$ & & 0.374 & & 0.041 & & ${ }^{* *} \mathrm{SC}$ \\
\hline $\mathrm{HC}$ & $141 \pm 20(10)$ & n.s. sc & $504 \pm 67(7)$ & ${ }^{*} \mathrm{SC}$ & 3.6 & $\begin{array}{l}0.001 \\
*^{*} \text { SC }\end{array}$ & $2.6 \pm 0.5(6)$ & n.s. sc & $10.6 \pm 1.6(7)$ & n.s. sc & 4.1 & $\begin{array}{l}0.002 \\
{ }^{* *} \text { SC }\end{array}$ \\
\hline
\end{tabular}

The data are given as mean \pm SEM. The number of experiments is given in parenthesis. IC Inferior colliculus, HC Hippocampus, $P$ Probability value, $s C$ Šidák corrected significance level for 2 comparisons, n.s. Not significant, * $\mathrm{sc}$ : $P<0.025,{ }^{* *} P<0.005$. For critical significance levels, see Methods section

$P=0.015$; Fig. $\left.3 \mathrm{~b}_{3}\right)$ showing the presence of functional GlyT1 in IC and HC astrocytes.

As the inhibition of $I_{\text {Gly (max) }}$ was incomplete and GlyT2 was occasionally reported to be present in astrocytes [40, 49], we analyzed transcripts for GlyTs in single astrocytes. GlyT1 mRNA was detected in all IC astrocytes and about half of the $\mathrm{HC}$ astrocytes (IC; $\mathrm{n}=6 / 2 / 2$; HC: $n=9 / 2 / 2$; Fig. 3b). GlyT2 was never found in astrocytes but in the positive control (Additional file 3: Figure S3).

Interestingly, we never observed a glycine-induced outward current or changes in $R_{\mathrm{M}}$ (tested every $30 \mathrm{~s} \hat{=}$ $0.033 \mathrm{~Hz}$ ) upon the activation of putatively expressed GlyRs (not shown). However, glycine-induced outward currents and $R_{\mathrm{M}}$ changes upon short term activation of GlyRs during the first seconds of glycine wash-in might be overlooked due to the relatively slow exchange of ACSF in the recording chamber and concomitant slow rise of the neurotransmitter concentration in combination with receptor desensitization [50]. Thus, bath application of glycine is not a suitable approach to prove the presence of functional GlyRs. Therefore, we designed a new protocol for fast and focal pressure injection of neurotransmitters in combination with a voltage-clamp protocol including a higher frequency of test pulses assessing $R_{\mathrm{M}}$ changes now at $1 \mathrm{~Hz}$ (Additional file 2: Figure S2A).

We first assessed the suitability of this protocol on IC and $\mathrm{HC}$ neurons. Bipolar shaped IC neurons and CA1 pyramidal cells (Additional file 1: Figure $\mathrm{S} 1 A$ ) expressed time- and voltage-dependent inward and outward currents, respectively (Additional file 1: Figure $\mathrm{S} 1 B$ ). Upon focal glycine application, IC neurons and CA1 pyramidal cells exhibited a transient, fast declining outward current (Additional file 2: Figure $\left.\mathrm{S} 2 B_{1}, D_{1}\right)$. This was paralleled by an increase in the offset current induced by the test pulses resembling a strong reduction of $R_{M}$ (IC: $t_{1}-97.9 \pm 0.5 \%, n=11 / 4 / 4$, $P<0.001 ; \quad \mathrm{HC}: \quad t_{1}-41.2 \pm 6.2 \%, \quad n=4 / 2 / 2, \quad P=0.004$; Additional file 2: Figure $\mathrm{S} 2 B_{2-3}, D_{2-3}$ ). In the prolonged presence of glycine, $R_{\mathrm{M}}$ of IC neurons recovered partially, whereas $R_{\mathrm{M}}$ of CA1 pyramidal cells recovered completely (IC: $t_{10}:-90.9 \pm 2.5 \%$ of resting $R_{\mathrm{M}}, P<0.001$ compared to $t_{0} ; P=0.004$ compared to $t_{1} ; \mathrm{HC}: t_{10}:-4.5 \pm 7.0 \%$ of resting $R_{\mathrm{M}}, P=0.285$ compared to $t_{0} ; P=0.006$ compared to $t_{1}$ ). Both cases indicate desensitization of GlyRs (Additional file 2: Figure $\mathrm{S}_{2} B_{3}, D_{3}$ ), as previously reported for neurons in both regions $[50,51]$.

Subsequently, we used the focal application protocol on IC and $\mathrm{HC}$ astrocytes. Glycine induced an inward but no outward current at any time point during the $10 \mathrm{~s}$ application (Fig. 3c $c_{1-2}$ ). Furthermore, the offset current induced by the test pulses did not change. At $t_{1}(1 \mathrm{~s}$ after glycine application), $R_{\mathrm{M}}$ was not reduced (IC: $+8.4 \pm$ $3.6 \%, n=15 / 4 / 4, P=0.018 ; \mathrm{HC}:+2.9 \pm 4.0 \%, n=6 / 5 / 3$, $P=0.252$; Fig. $3 c_{3}$ ). Thus, $R_{M}$ was glycine-independent arguing against an activation of GlyRs. Taken together, IC and $\mathrm{HC}$ astrocytes expressed functional GlyT1, whereas GlyRs were only present in IC and HC neurons. Data are summarized in Tables 2 and 3.

\section{GAT expression in IC and HC astrocytes}

GATs are present in astrocytes of various brain regions $[15,16]$. Here, we analyzed the expression of different functional GATs in $\mathrm{IC}$ and $\mathrm{HC}$ astrocytes. GATs and $\mathrm{GABA}_{\mathrm{A}}$ Rs mediate - under our experimental conditions - an inward and outward current, respectively. The wash-in of GABA induced a transient inward current $\left(I_{\mathrm{GABA}}\right)$ that peaked usually within the first minute $\left(I_{\text {GABA (max) }}\right.$; Fig. $\left.4 \mathrm{a}_{1-2}\right)$. Notably, $I_{\text {GABA }(\max )}$ was larger in $\mathrm{HC}$ astrocytes (IC: $327 \pm 35 \mathrm{pA}, n=14 / 11 / 10$; $\mathrm{HC}$ : $504 \pm 67$ pA, $n=7 / 7 / 5 ; \quad P=0.009 ;$ Fig. $\left.4 \mathrm{a}_{3}\right)$. Upon

Table 3 The effect of glycine and GABA on astrocytic and neuronal membrane resistance

\begin{tabular}{|c|c|c|c|c|c|}
\hline Region & Cell type & $\Delta R_{\mathrm{M}(\mathrm{Gly})}[\%]$ & $P$ & $\Delta R_{\mathrm{M}(\mathrm{GABA})}[\%]$ & $P$ \\
\hline \multirow[t]{2}{*}{ IC } & Astrocyte & $+8.4 \pm 3.6(15)$ & 0.018 n.s. sc & $+1.1 \pm 4.4(15)$ & 0.403 n.s. sc \\
\hline & Neuron & $-97.9 \pm 0.5(11)$ & $0.000 * * *_{\mathrm{SC}}$ & $-98.9 \pm 0.1(11)$ & $0.000{ }^{* * *} \mathrm{SC}$ \\
\hline \multirow[t]{2}{*}{$\mathrm{HC}$} & Astrocyte & $+2.9 \pm 4.0(6)$ & 0.252 n.s. sc & $-7.6 \pm 1.1(8)$ & $0.000 * *{ }^{*} \mathrm{sC}$ \\
\hline & Neuron & $-41.2 \pm 6.2(4)$ & $0.004{ }^{*} \mathrm{SC}$ & $-73.5 \pm 5.7(5)$ & $0.000 * *{ }^{*} \mathrm{SC}$ \\
\hline
\end{tabular}

The data are given as mean \pm SEM. The number of experiments is given in parenthesis. IC Inferior colliculus, $H C$ Hippocampus, $P$ Probability value, sC Šidák corrected significance level for 3 comparisons, n.s. Not significant, ${ }^{*}$ sc: $P<0.017,{ }^{* * *}$ sc: $P<0.0003$. For critical significance levels, see Methods section. $\Delta R_{M}$ is given for $\mathrm{t}_{1}$ (1 $\mathrm{s}$ after focal application of neurotransmitter) 
prolonged application, $I_{\mathrm{GABA}}$ recovered occasionally to a lower steady-state level in some recordings. Similar to $I_{\mathrm{GABA}}, \mathrm{GABA}$ induced a reversible depolarization (IC:

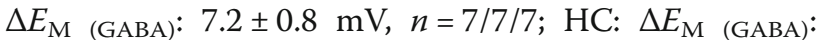
$10.6 \pm 1.6 \mathrm{mV}, n=7 / 7 / 5 ; P=0.041$; Fig. 4b). Both $I_{\mathrm{GABA}}$ and $\Delta E_{\mathrm{M}}$ (GABA) indicate the presence of functional GATs. Noticeably, GABA-induced transients were 2-4fold larger than the above-described glycine-induced transients. In addition, this difference was more prominent in $\mathrm{HC}$ astrocytes than in IC astrocytes (Table 2).

To assess the different GAT isoforms being expressed in IC and HC astrocytes, we focally applied GABA and analyzed the sensitivity of $I_{\mathrm{GABA}}$ to the non-competitive GAT-1 and GAT-3 antagonists NO711 and SNAP5114, respectively (Fig. 5a $\mathrm{a}_{1-2}$ ). The two antagonists reduced $I_{\mathrm{GABA}}(\max )$ by about $20-40 \%$ (IC: NO711: $19 \pm 4 \%, n=4$ / 4/2, $P=0.007$; SNAP5114: $22 \pm 4 \%, n=4 / 4 / 4, P=0.003$; HC: NO711: $28 \pm 6 \%, n=8 / 8 / 5, P<0.001$; SNAP5114: $43 \pm 6 \%, n=7 / 7 / 4, \quad P=0.001$; Fig. $\left.5 \mathrm{a}_{3}\right)$ showing the presence of functional GAT-1 and GAT-3. NO711 and SNAP5114 themselves had no effect on the membrane current. Simultaneously inhibiting GAT-1 and GAT-3 led to an incomplete reduction of $I_{\mathrm{GABA}}$ (max) (Fig. $5 \mathrm{a}_{1-2}$ ). This can either result from a low antagonist concentration that was chosen in order to ensure specificity of the substances or from the presence of further GATs, i.e. GAT-2 (Slc6A13) and BGT-1 (Slc6A12) [16]. The latter case was addressed analyzing transcripts for the four cloned GATs in single astrocytes. All tested IC astrocytes exhibited transcripts for GAT-1 and GAT-3, whereas these transporters are present in about half of the $\mathrm{HC}$ astrocytes. It has to be pointed out that transcripts for GAT-1 and GAT-3 were found in 3/7 HC astrocytes, whereas they were not detected in $3 / 7$ cases. In those cells transcripts for Kir4.1 were found, which proved successful RNA extraction. One HC astrocyte expressed only transcripts for GAT-1. However, transcripts for GAT-2 and BGT-1 were only detected in the positive

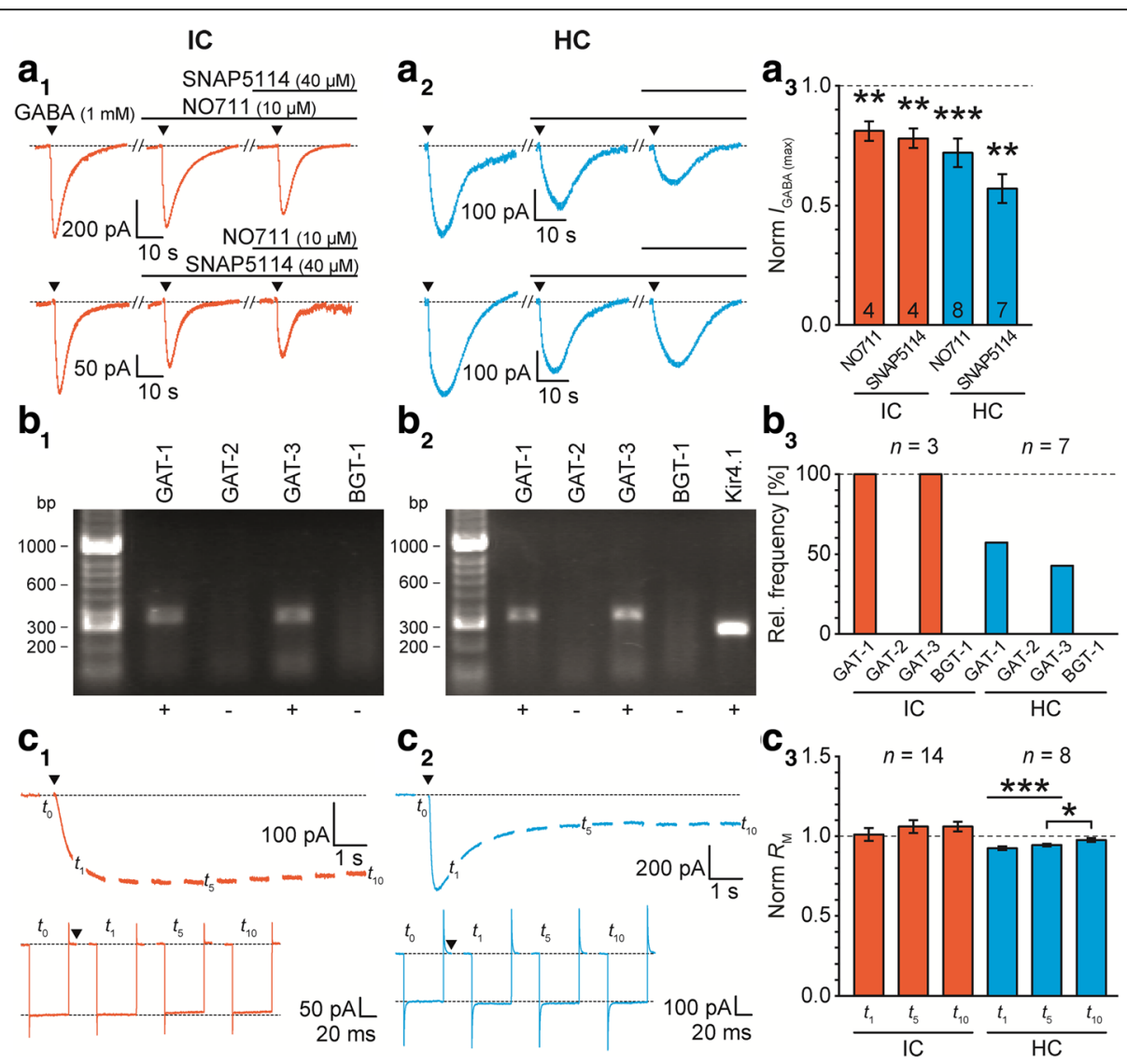

Fig. $5 \mathrm{IC}$ and HC astrocytes express GAT-1 and GAT-3. a: Focal application of GABA (1 mM, $0.5 \mathrm{~s}$; triangles) elicited an $I_{G A B A}\left(E_{H}=-85 \mathrm{mV} ; \mathrm{a}_{1-2}\right)$. The non-competitive antagonists for GAT-1 (NO711, $10 \mu \mathrm{M})$ and GAT-3 (SNAP5114, $40 \mu \mathrm{M})$ reduced $I_{\text {GABA }(\max )}\left(\mathrm{a}_{3}\right)$. b: Single-cell RT-PCR revealed transcripts for GAT-1 and GAT-3 in all IC astrocytes and about half of the HC astrocytes. Transcripts for GAT-2 and BGT-1 were never present. c: Focal application of GABA (1 mM, 10 s; triangle) induced a long lasting inward current ( $E_{\mathrm{H}}=-85 \mathrm{mV} ; \mathrm{C}_{1-2}$, top). Responses to test pulse (see Additional file 2: Figure S2A) were used to calculate $R_{\mathrm{M}}$ at $t_{0}, t_{1}, t_{5}$, and $t_{10}$ ( $c_{1-2}$, bottom). Upon GABA application, $R_{\mathrm{M}}$ was transiently reduced exclusively in HC astrocytes $\left(c_{3}\right)$. The number of recorded cells $(n)$ is given within the diagrams. Shown are mean values \pm SEM. Significance levels in panel $c_{3}$ were Šidák corrected for three comparisons (see Methods section). bp: base pairs 
control (Additional file 3: Figure S3), but not in individual IC or $\mathrm{HC}$ astrocytes (IC: $n=3 / 2 / 2 ; \mathrm{HC}: \mathrm{n}=7$ / 6/5; Fig. 5b).

Astrocytes, for example in the $\mathrm{HC}$, express $\mathrm{GABA}_{\mathrm{A}} \mathrm{Rs}$ $[21,22]$. Accordingly, $I_{\mathrm{GABA}}(\max )$ might be underestimated if $\mathrm{GABA}_{\mathrm{A}} \mathrm{R}$-mediated $\mathrm{Cl}^{-}$influx causes an outward current that counteracts the GAT-mediated inward current. To verify this, we performed fast and focal pressure injection of GABA and assessed $R_{M}$ changes.

Positive controls on $\mathrm{GABA}_{\mathrm{A}} \mathrm{R}$ expressing IC and $\mathrm{HC}$ neurons $[30,50,52]$ showed the suitability of the experimental configuration to reveal $\mathrm{GABA}_{\mathrm{A}} \mathrm{R}$ activation. Focal GABA application induced a transient, fast declining outward current (Additional file 2: Figure $\mathrm{S} 2 C_{1}, E_{1}$ ). This was paralleled by strong increase in the offset current induced by the test pulses resembling an eminent reduction of $R_{\mathrm{M}}$ (IC: $t_{1}:-98.9 \pm 0.1 \%, n=11 / 6 / 6, P<0.001$; HC: $t_{1}:-73.5 \pm$ $5.7 \%, n=5 / 3 / 2, P<0.001$; Additional file 2: Figure $S 2 C_{2-3}$, Additional file 2: Figure $S 2 E_{2-3}$ ). In the prolonged presence of GABA, $R_{\mathrm{M}}$ of IC neurons recovered partially indicating minimal desensitization of $\mathrm{GABA}_{\mathrm{A}} \mathrm{Rs}\left(t_{10}:-96.4 \pm 0.4 \%\right.$ of resting $R_{\mathrm{M}}, P<0.001$ compared to $t_{0} ; P<0.001$ compared to $t_{1}$; Additional file 2: Figure $\mathrm{S} 2 C_{3}$ ) as previously reported [50]. In contrast, $R_{\mathrm{M}}$ of CA1 pyramidal cells recovered completely indicating strong desensitization of $\mathrm{GABA}_{\mathrm{A}} \mathrm{Rs}$ $\left(t_{10}:+2.8 \pm 9.4 \%\right.$ of resting $R_{\mathrm{M}}, P=0.250$ compared to $t_{0}$; $P=0.003$ compared to $t_{1}$; Additional file 2: Figure $\mathrm{S} 2 E_{3}$ ) as previously reported [53, 54].

Subsequently, we did focal application and analyzed putative GABA $\mathrm{A}_{\mathrm{A}} \mathrm{R}$-mediated $R_{\mathrm{M}}$ changes in IC and $\mathrm{HC}$ astrocytes (Fig. 5c). At any time, GABA induced an inward but no outward current (Fig. $5 c_{1-2}$ ). In IC astrocytes, the offset current induced by the test pulses did not change (Fig. $\left.5 c_{1}\right)$. Accordingly, at $t_{1} R_{\mathrm{M}}$ was not reduced $(+1.1 \pm 4.4 \%$, $n=15 / 5 / 5, P=0.403$; Fig. $\left.5 c_{3}\right)$. Thus, $R_{\mathrm{M}}$ was GABAindependent arguing against an activation of $\mathrm{GABA}_{\mathrm{A}} \mathrm{Rs}$. In $\mathrm{HC}$ astrocytes however, GABA increased the offset current in response to the test pulses (Fig. $5 c_{2}$ ). In turn, $R_{\mathrm{M}}$ was reduced $\left(t_{1}:-7.6 \pm 1.1 \%, n=8 / 5 / 2, P<0.001\right.$; Fig. $\left.4 \mathrm{c}_{3}\right)$ demonstrating activation of $\mathrm{GABA}_{\mathrm{A}} \mathrm{Rs}$ in $\mathrm{HC}$ astrocytes. In the prolonged presence of GABA, $R_{\mathrm{M}}$ recovered completely, indicating desensitization of $\mathrm{GABA}_{\mathrm{A}} \mathrm{Rs}\left(t_{10}:-2.4 \pm 1.3 \%\right.$ of resting $R_{\mathrm{M}}, P=0.055$ compared to $t_{0} ; P<0.001$ compared to $t_{1}$; Fig. $5 \mathrm{c}_{3}$ ). Thus, $I_{\mathrm{GABA}}$ (max) was not contaminated by $\mathrm{GABA}_{\mathrm{A}} \mathrm{R}$ activation as it was not determined within the first $10 \mathrm{~s}$ of GABA wash-in. Taken together, IC and HC astrocytes co-expressed functional GAT-1 and GAT-3, whereas $\mathrm{GABA}_{\mathrm{A}}$ Rs were only found in $\mathrm{HC}$ astrocytes. Data are summarized in Tables 2 and 3.

\section{Region-dependent transporter kinetics}

As we observed that the $I_{\mathrm{GABA}(\max )} / I_{\mathrm{Gly}}$ (max) ratio was larger in HC compared to IC (Table 2) we speculated about putative additional differences between those nuclei regarding transporters kinetics. Thus, we analyzed rise time $(10-90 \%)$ and decay time $(90-10 \%)$ of $I_{\mathrm{Gly}}$ and $I_{\mathrm{GABA}}$ in IC and $\mathrm{HC}$ astrocytes resulting from focal application of glycine and GABA (Fig. $6 \mathrm{a}_{1}, \mathrm{~b}_{1}$ ). The rise time of $I_{\text {Gly }}$ was much shorter in $\mathrm{HC}$ astrocytes (IC: $1.32 \pm 0.08 \mathrm{~s}$, $n=12 / 5 / 5$; HC: $0.70 \pm 0.15$ s, $n=8 / 7 / 4 ; P=0.002$; Fig. $6 a_{2}$ ). Additionally, the decay time of $I_{\mathrm{Gly}}$ was shorter in $\mathrm{HC}$ astrocytes, too (IC: $11.83 \pm 0.83 \mathrm{~s}, n=12 / 5 / 5$; HC: $8.35 \pm 0.64$ s, $n=8 / 7 / 4 ; P=0.002$; Fig. $6 \mathrm{a}_{3}$ ). Together, $\mathrm{HC}$ astrocytes exhibited faster kinetics for $I_{\mathrm{Gly}}$.

Similarly, we analyzed the kinetics of $I_{\mathrm{GABA}}$ (Fig. 6b). Here, IC astrocytes exhibited a much shorter rise time (IC: $1.15 \pm 0.10 \mathrm{~s}, n=8 / 8 / 8$; HC: $2.29 \pm 0.27 \mathrm{~s}, n=19 / 19 / 6$; $P<0.001$; Fig. $\left.6 b_{2}\right)$. The decay time of $I_{\mathrm{GABA}}$ was not different between IC and HC astrocytes (IC: $12.29 \pm 0.68 \mathrm{~s}$, $n=8 / 8 / 8 ;$ HC: $11.17 \pm 0.54$ s, $n=19 / 19 / 6 ; \quad P=0.123$; Fig. $\left.6 b_{3}\right)$. Taken together, our data demonstrate that transporter-mediated currents were heterogeneous with respect to glycine and GABA as well as the brain region. $\mathrm{HC}$ astrocytes exhibited faster $I_{\mathrm{Gly}}$ kinetics, whereas IC astrocytes partially showed faster $I_{\mathrm{GABA}}$ kinetics. Data are summarized in Table 4.

In summary, our results show that SR101-labeled cells in the IC and $\mathrm{HC}$ exhibited properties of classical astrocytes. In all IC and about half of the $\mathrm{HC}$ astrocytes, GlyT1, GAT-1, and GAT-3 were present, whereas GlyT2, GAT-2, and BGT-1 were not found. In both regions, astrocytes exhibited a stronger GAT than GlyT activity. However, in $\mathrm{HC}$ astrocytes the $I_{\mathrm{GABA}}(\max ) / I_{\mathrm{Gly}}(\max )$ ratio was remarkably higher. In comparison to IC astrocytes $\mathrm{HC}$ astrocytes showed faster kinetics for the transport of glycine and slower kinetics for the transport of GABA. Finally, GlyRs could not be detected in astrocytes of IC and $\mathrm{HC}$. However, expression of $\mathrm{GABA}_{\mathrm{A}}$ Rs was heterogeneous - it was found in $\mathrm{HC}$ but not in IC astrocytes.

\section{Discussion}

In the present study, we investigated the expression and function of GlyTs and GATs in astrocytes from IC and HC. In both regions, astrocytes generally expressed the three inhibitory neurotransmitter transporters GlyT1, GAT-1 and GAT-3, whereas GlyT2, GAT-2, and BGT-1 were not detected. Remarkably, IC astrocytes exhibited larger $I_{\mathrm{Gly}(\max )}$ and smaller $I_{\mathrm{GABA}(\max )}$ compared to $\mathrm{HC}$ astrocytes. In turn, this resulted in a higher $I_{\mathrm{GABA}}(\max ) /$ $I_{\text {Gly }(\max )}$ ratio in $\mathrm{HC}$ astrocytes.

\section{Basic properties of IC and HC astrocytes}

Astrocytes were labeled with SR101, by which classical astrocytes in acute tissue slices - containing the superior olivary complex (SOC) or the $\mathrm{HC}$ - can be identified [19, 41, 42, 55]. We mentioned before that in the IC SR101 labels small sized and highly branched cells [19]. However, their identity was not verified yet by electrophysiological recordings. Here 

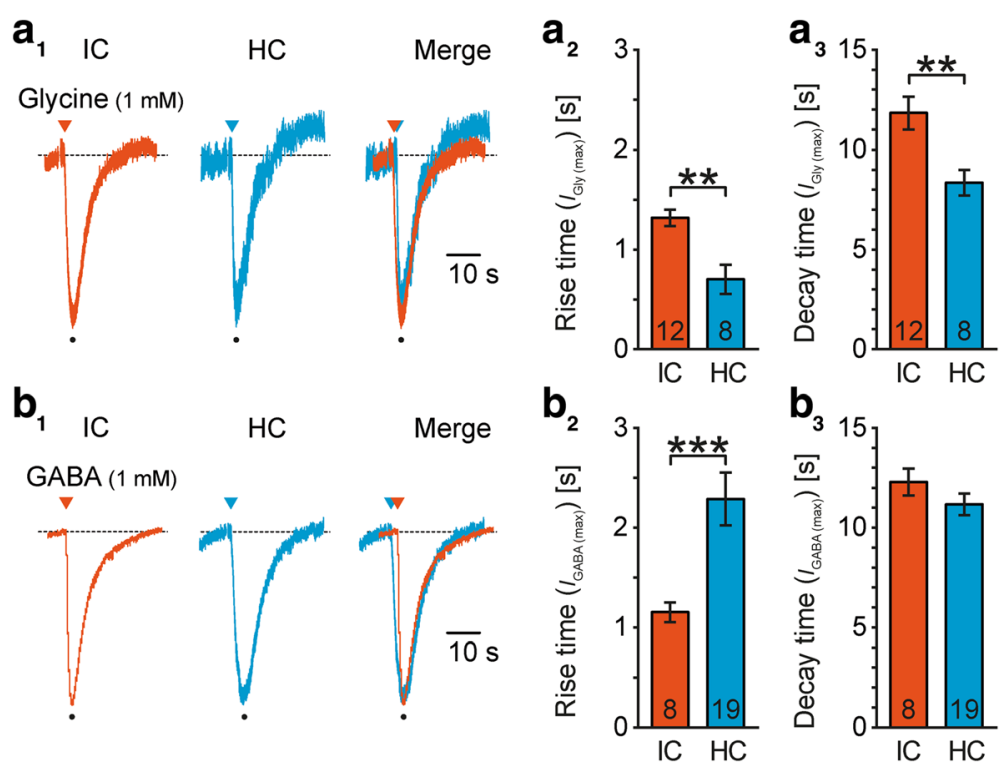

Fig. 6 Region-dependent kinetics of $I_{G l y}$ and $I_{G A B A}$. a: $I_{G l y}$ kinetics. Focal application of glycine $\left(1 \mathrm{mM}, 0.5 \mathrm{~s}\right.$; triangles) elicited an $I_{G l y}\left(E_{H}=-85 \mathrm{mV}\right)$ in IC (left) and HC (middle) astrocytes. Merged traces were peak aligned (right; $\left.a_{1}\right)$. IC astrocytes exhibited longer rise time (a $\left.a_{2} ; 10-90\right)$ and decay time (a $\left.a_{3} ; 90-10\right)$ compared to HC astrocytes. b: $I_{G A B A}$ kinetics. Focal application of GABA (1 mM, 0.5 s; triangles) elicited an $I_{G A B A}\left(E_{H}=-85 \mathrm{mV}\right)$ in IC (left) and HC (middle) astrocytes. Merged traces were peak aligned (right; $\left.b_{1}\right)$. IC astrocytes exhibited a shorter rise time compared to HC astrocytes $\left(b_{2}\right)$. The decay time was not significantly different $\left(b_{3}\right)$. The number of recorded cells $(n)$ is given within the diagrams. Shown are mean values \pm SEM

we show that SR101-labeled IC cells exhibit a highly negative $E_{\mathrm{M}}$ and a low $R_{\mathrm{M}}$. They are not NG2 glia as these exhibit completely different electrophysiological properties, i.e. a more positive $E_{\mathrm{M}}$, a tremendously higher $R_{\mathrm{M}}$, and currents through voltage-activated sodium channels [42, 56-58]. Furthermore, they are unlikely to be oligodendrocytes as they are if at all just weakly labeled by SR101 [41]. In contrast, SR101-labeled IC cells exhibited a non-linear or linear current-voltage relationship corresponding to non-passive and passive astrocytes, respectively, which are found throughout the auditory brainstem (Fig. 1) [19, 41, 55, 59, 60]. Furthermore, these from now on IC astrocytes-termed cells were distributed homogeneously within the nucleus (Fig. 1) like astrocytes in SOC nuclei [19, 41]. HC astrocytes exhibited properties like reported in previous studies, e.g. [42, 56].

\section{IC and HC astrocytes express functional GlyT1, GAT-1, and GAT-3}

Glycine and GABA activate respective transporters that mediate an inward current and a concomitant depolarization due to their stoichiometry: 1 glycine/1 GABA: $2 \mathrm{Na}^{+}: 1 \mathrm{Cl}^{-}$
$[15,17]$. Both inward current and depolarization sometimes partially recovered in the prolonged presence of the agonist (Figs. 2 and 4). This was observed before in LSO astrocytes and may be due to a reduced driving force [19]. Both IC and $\mathrm{HC}$ astrocytes showed sarcosine-sensitive $I_{\mathrm{Gly}}$ (max), demonstrating the presence of functional GlyT1 (Fig. 3). Sarcosine is a competitive agonist and therefore inhibited just about $60-70 \%$ of $I_{\mathrm{Gly}(\max )}[61]$. Thus, the co-expression of the neuron-typical GlyT2 could not be excluded per se. GlyT2 was reported to be present occasionally in astrocytes $[40,49]$. However, here we never found transcripts for GlyT2 in IC and $\mathrm{HC}$ astrocytes indicating the absence of GlyT2. GlyT1 mRNA was present in all IC astrocytes sufficiently explaining $I_{\mathrm{Gly}}$. However, GlyT1 transcripts were found only in about half of the $\mathrm{HC}$ astrocytes (Fig. 3). There are several possible explanations: 1) Although the scRTPCR reliably detected GlyT1 transcripts in the positive controls, it was eventually not sensitive enough to detect single transcripts in all $\mathrm{HC}$ astrocytes. 2) There is effectively a mosaic expression of GlyT1. However, all recorded HC astrocytes exhibited an $I_{\text {Gly }}$ (Fig. 2). Thus, HC astrocytes

Table 4 Kinetics of glycine- and GABA-induced currents in IC and HC astrocytes

\begin{tabular}{|c|c|c|c|c|c|c|c|c|}
\hline \multirow[t]{2}{*}{ Region } & \multicolumn{4}{|l|}{$I_{\text {Gly }}$} & \multicolumn{4}{|l|}{$I_{\text {GABA }}$} \\
\hline & Rise time $[s]$ & $P$ & Decay time $[\mathrm{s}]$ & $P$ & Rise time $[\mathrm{s}]$ & $P$ & Decay time (s] & $P$ \\
\hline IC & $1.32 \pm 0.08(12)$ & \multirow{2}{*}{$0.002^{* *}$} & $11.83 \pm 0.83(12)$ & \multirow{2}{*}{$0.002^{* *}$} & $1.15 \pm 0.10$ & \multirow{2}{*}{$0.000^{* * *}$} & $12.29 \pm 0.68(8)$ & \multirow{2}{*}{$\begin{array}{l}0.123 \\
\text { n.s }\end{array}$} \\
\hline $\mathrm{HC}$ & $0.70 \pm 0.15$ & & $8.35 \pm 0.64$ & & $2.29 \pm 0.27(19)$ & & $11.17 \pm 0.54$ & \\
\hline
\end{tabular}

The data are given as mean \pm SEM. The number of experiments is given in parenthesis. IC Inferior colliculus, HC Hippocampus, $P$ Probability value, $n$.s. Not significant ${ }^{* *}: P<0.01,{ }^{* * *}: P<0.001$ 
putatively express further transporters that are capable to transport glycine. The neutral amino acid transporter ASCT2 (Slc1A5) as well as sodium-coupled neutral amino acid transporters (system N) SNAT3 (Slc38A3) and SNAT5 (Slc38A5) are expressed by astrocytes and transport glycine, but are electroneutral and accordingly do not generate currents [62-65]. 3) HC astrocytes are extensively coupled [66-69] and allow direct electrical communication between neighboring astrocytes [70-72]. Here, about half of the HC astrocytes lacked GlyT1 expression, but can be expected to be surrounded by and coupled to GlyT1 expressing HC astrocytes. Therefore, GlyT1 negative astrocytes might indirectly experience $I_{\mathrm{Gly}}$.

Likewise, IC and HC astrocytes exhibited NO711- and SNAP5114-sensitive $I_{\mathrm{GABA}}(\max )$ showing the co-expression of functional GAT-1 and GAT-3 in both regions (Fig. 5). Hitherto, in the HC GAT-1 and GAT-3 were attributed to interneurons and astrocytes, respectively [21,37]. To our surprise, we found prominent expression of functional GAT-1 in HC astrocytes. NO711 and SNAP5114 inhibited $I_{\text {GABA (max) }}$ by about 20 to $40 \%$ (Fig. 5), which is similar to our former study on LSO astrocytes [19]. However, simultaneous administration of NO711 and SNAP5114 did not completely abolish $I_{\mathrm{GABA}}(\max )$ (Fig. 5). Both antagonists dose-dependently inhibit respective GATs [21]. As we here used a low drug concentration to retain the specificity of GAT inhibitors [16] it was not expected to achieve a complete blockage. However, to that point our data did not exclude the possibility of co-expression of further GATs, such as GAT-2 or BGT-1. The latter are predominantly found at the meninges and neuronal somata, respectively [16]. In accordance, we found only transcripts for GAT-1 and GAT-3 but not for GAT-2 and BGT-1 in IC and HC astrocytes. These results indicate that $I_{\mathrm{GABA}}$ was solely mediated by GAT-1 and GAT-3 (Fig. 5). Surprisingly, GAT-1 and GAT-3 mRNA exhibited a mosaic pattern in $\mathrm{HC}$ astrocytes. In $3 / 7$ cases $\mathrm{HC}$ astrocytes did not exhibit transcripts for any GAT. There are two possible explanations: 1) Although the scRT-PCR detected transcripts in the positive controls, it was not sensitive enough to detect single transcripts on the single cell level. 2) There is effectively a mosaic expression pattern. However, the second explanation contrasts with the finding that all $\mathrm{HC}$ astrocytes exhibited $I_{\mathrm{GABA}}$ that was always sensitive to the GAT-1 and GAT-3 inhibitor NO711 and SNAP5114, respectively (Figs. 4 and 5). Again, the extensive coupling of and direct electrical communication between $\mathrm{HC}$ astrocytes [66-72] could explain why $I_{\mathrm{GABA}}$ was recorded in all cells independent from GAT expression.

The co-expression of GlyTs and GATs in the same astrocyte raises the question of transporter interference. Such interference of different transporters was seen before $[6,73,74]$. In a previous study on LSO astrocytes, we could show that GlyT and GAT activity influence each other [19]. The reciprocal reduction of activity likely refers to changes in their commonly used gradients for $\mathrm{Na}^{+}$and $\mathrm{Cl}^{-}$. Those gradients become weakened upon transporter activation thereby reducing the driving force for the transport. Especially in the IC, where neurons simultaneously receive glycinergic and GABAergic synaptic inputs $[29,30]$, transporter interference might occur during synchronous activation of astrocytic GlyTs and GATs [15]. However, it remains to be elucidated to which extend this interplay takes place and how altered neurotransmitter clearance putatively modulates neuronal signaling $[15,17,18]$.

Taken together, all IC and about half of the HC astrocytes expressed functional GlyT1, GAT-1, and GAT-3. In this respect, these astrocytes can express the same combination of inhibitory neurotransmitter transporters like astrocytes located in LSO, thalamus, cortex or Bergmann glia in the cerebellum or Müller cells in the retina [15, 19, 75-80]. The potentially heterogeneous expression in $\mathrm{HC}$ astrocytes could be indicative of functional domains in which glycinergic transmission arising from excitatory projections and GABAergic transmission from interneurons are segregated from each other.

\section{Transporter currents are not contaminated by ionotropic receptor activation}

Both glycine and GABA act on respective transporters and ionotropic receptors. While activation of GlyTs and GATs by exogenous accessible neurotransmitters necessarily causes an inward current, activation of GlyRs and $\mathrm{GABA}_{\mathrm{A}}$ Rs can result in either an inward current or an outward current. The underlying $\mathrm{Cl}^{-}$efflux or influx depends on $\left[\mathrm{Cl}^{-}\right]_{\mathrm{i}}$ and subsequently on $E_{\mathrm{Cl}}$. Under physiological conditions astrocytic $\left[\mathrm{Cl}^{-}\right]_{\mathrm{i}}$ amounts to about $30 \mathrm{mM}$ [81] causing an inward current and concomitant depolarization upon receptor activation. However, our pipette solution contained $2 \mathrm{mM} \mathrm{Cl}^{-}$and receptor activation would have caused an outward current. In our recordings, we never observed glycine- or GABA-induced outward currents in IC and $\mathrm{HC}$ astrocytes (e.g. Figs. 2 and 4), which was surprising as at least $\mathrm{HC}$ astrocytes express functional $\mathrm{GABA}_{\mathrm{A}} \mathrm{Rs}[21,22]$. Two possible scenarios could explain this discrepancy: 1 ) The $\mathrm{GABA}_{\mathrm{A}} \mathrm{R}$-mediated outward current was too small and consecutively masked by the large GAT-mediated inward current. This in turn would suggest that the amount of GAT-mediated inward current would be underestimated. 2) $\mathrm{GABA}_{\mathrm{A}}$ Rs rapidly desensitize [53, 54, 82]. In combination with slow wash-in of GABA in our experiments, this early desensitization might hamper the accurate detection of $\mathrm{GABA}_{\mathrm{A}} \mathrm{R}$ activation. To answer the question of masked activation and/or desensitization of ionotropic receptors we measured $R_{\mathrm{M}}$ changes that could result from increased membrane 
permeability (see Methods). Proof of principle experiments on GlyR and $\mathrm{GABA}_{\mathrm{A}} \mathrm{R}$ expressing $\mathrm{IC}$ and $\mathrm{HC}$ neurons validated the method (Additional file 2: Figure S2). Our results convincingly demonstrated the capability to detect $R_{\mathrm{M}}$ changes upon GlyR and $\mathrm{GABA}_{\mathrm{A}} \mathrm{R}$ activation with the utilized test pulse protocol.

With this tool at hand, we were able to detect $\mathrm{GABA}_{\mathrm{A}} \mathrm{R}$ activation in $\mathrm{HC}$ astrocytes (Fig. 5). $\mathrm{GABA}_{\mathrm{A}} \mathrm{R}$ activation was detected by temporary $R_{\mathrm{M}}$ reduction that vanished within $10 \mathrm{~s}$ indicating receptor desensitization. However, we never observed any outward current that had to arise from $\mathrm{Cl}^{-}$influx due to the low $\left[\mathrm{Cl}^{-}\right]_{\mathrm{i}}$ of the intracellular solution. We reason that any small $\mathrm{Cl}^{-}$ influx-mediated outward current is instantly masked by strong electrogenic transporter current. Nonetheless, $I_{\mathrm{GABA}}(\max )$, which was measured earliest after $10 \mathrm{~s}$, was not contaminated by $\mathrm{GABA}_{\mathrm{A}} \mathrm{R}$-mediated currents. The $R_{\mathrm{M}}$ reduction in $\mathrm{HC}$ astrocytes was rather small $(\sim 8 \%)$ compared to $\mathrm{HC}$ neurons $(\sim 74 \%)$. Astrocytes express various $\mathrm{K}^{+}$channels that are constitutively open at resting conditions (inwardly rectifying $\mathrm{K}^{+}$channels, twopore-domain $\mathrm{K}^{+}$channels) $[46,83]$. In turn, these channels cause the very high $\mathrm{K}^{+}$conductance observed in astrocytes [44]. Accordingly, it is not surprising that the $R_{\mathrm{M}}$ reduction was relatively small. At the same time, IC astrocytes exhibited no $R_{\mathrm{M}}$ reduction upon GABA application (Fig. 5). Thus, either $\mathrm{GABA}_{\mathrm{A}}$ Rs are absent or their amount is essentially not high enough to be relevant. Interestingly, using this method on LSO astrocytes we detected a small $R_{\mathrm{M}}$ reduction indicating the presence of $\mathrm{GABA}_{\mathrm{A}}$ Rs (Vanessa Augustin and Simon Wadle, unpublished). We previously reported that $I_{\mathrm{GABA}}$ in LSO astrocytes mainly constitutes of GAT-mediated current [19]. Similar to HC astrocytes, the GABA-induced $R_{\mathrm{M}}$ reduction in LSO astrocytes vanished within $10 \mathrm{~s}$ after the beginning of GABA application. Thus, our previously reported $I_{\mathrm{GABA}}$ (max) in LSO astrocytes was not contaminated by $\mathrm{GABA}_{\mathrm{A}} \mathrm{R}$ activation.

Similarly, we used the same method to examine a possible influence of GlyR activation onto our recorded $I_{\text {Gly }}$ (max). We could show that neither IC nor HC astrocytes exhibited glycine-induced $R_{\mathrm{M}}$ changes or outward currents (Figs. 2 and 3). Likewise, LSO astrocytes lack glycine-induced $R_{\mathrm{M}}$ changes (Vanessa Augustin and Simon Wadle, unpublished). Accordingly, functional GlyRs appear to be absent in those astrocytes. This is consistent with the observation that GlyRs were described only in astrocytes located in most caudal brain regions, i.e. spinal cord and caudal brainstem (ventral respiratory group) [20, 24, 25]. However, this contrasts with the wide distribution of $\mathrm{GABA}_{\mathrm{A}} \mathrm{Rs}$ throughout the brain [22]. In summary, $I_{\mathrm{Gly}(\max )}$ and $I_{\mathrm{GABA}}(\max )$ were not affected by GlyRs and $\mathrm{GABA}_{\mathrm{A}} \mathrm{Rs}$, respectively, and the transporter currents were accordingly not underestimated.

\section{Activity and kinetics of GlyTs and GATs}

IC and $\mathrm{HC}$ astrocytes are differently capable to take up glycine and GABA (Table 2). While there is no statistical difference for glycine transport among the two brain regions, the GABA transport is stronger in $\mathrm{HC}$ astrocytes. In the LSO, which is located more caudal compared to IC and $\mathrm{HC}$, astrocytes exhibit a similar capability to take up glycine. However, their ability for GABA clearance is much lower [19]. Thus, astrocytic $I_{\mathrm{GABA}}(\max )$ increases from caudal to rostral brain regions ( $\mathrm{LSO}<\mathrm{IC}<\mathrm{HC}$ ). Consequently, the ratio of $I_{\mathrm{GABA}(\max )} / I_{\mathrm{Gly}}(\max )$ is elevated in more rostral brain regions $(\mathrm{HC}(3.6)>\mathrm{IC}(1.9)>\mathrm{LSO}$ (1.6; data from [19])). This was expected, as the need to take up GABA rather than glycine is higher in rostral brain regions, which arises from the glycine-to-GABA shift as the predominant inhibitory neurotransmitter [2, 3, $9,10,29,30]$. Noticeably, GlyT-mediated $I_{\text {Gly }}(\max )$ substantially persists in $\mathrm{HC}$ astrocytes. This allows the clearance of glycine that is co-released from excitatory presynaptic terminals $[11,12]$. Taken together, $I_{\mathrm{Gly}}(\max )$ is similar in the three brain regions, whereas $I_{\mathrm{GABA}}(\max )$ as well as the $I_{\mathrm{GABA}}(\max ) / I_{\mathrm{Gly}}(\max )$ ratio are regiondependent and increases with the prevalence of GABA as inhibitory neurotransmitter.

Beside inter-region differences of amplitudes, we additionally found region-dependent alterations of the kinetics of transporter-mediated currents (Table 4). Whereas IC astrocytes exhibit similar kinetics for the transport of glycine and GABA, HC astrocytes are marked by faster glycine and slower GABA transport. However, LSO astrocytes generally outperform IC and $\mathrm{HC}$ astrocytes regarding kinetics of GlyTs (rise time: $1.05 \pm 0.18 \mathrm{~s}$; decay time: $4.88 \pm 1.11 \mathrm{~s} ; n=6 / 6 / 6$ ) and GATs (rise time: 0.61 $\pm 0.13 \mathrm{~s}$; decay time: $4.52 \pm 0.52 \mathrm{~s} ; n=12 / 12 / 11$; data from [19]). GlyTs and GATs can be modulated by several mechanisms: e.g., enhancement of transporter activity can be achieved by transporter glycosylation and $\left[\mathrm{Ca}^{2+}\right]_{\mathrm{i}}$ elevation [84-86], whereas decrease of transporter activity can be caused by activation of protein kinase $\mathrm{C}$ and de-glycosylation [84, 85, 87-89]. If one or more of those mechanisms are relevant in astrocytes of the three brain regions, is yet unexplored. However, the different transport kinetics correlate with different precision of signal processing in those three brain regions. The auditory system in general requires temporal precise coding to compute correctly e.g. interaural time and level differences in the medial superior olive and the LSO, respectively, and synapses show relatively weak depression allowing high rates of synaptic transmission $[4,90-$ 92]. Furthermore, the synaptic signaling in the LSO is considerably faster and more precise compared to the hippocampus [93]. Like the LSO, the IC belongs to the auditory brainstem. However, it is not used for sound source localization, but serves as an information hub. 
Thus, the IC can tolerate a slower and less precise synaptic transmission. As the rate of neurotransmitter transporter activity determines the extent of synaptic transmission [17, 18], the fast transmitter uptake into LSO astrocytes to terminate quick synaptic transmission is in favor of fast and precise neuronal signaling. In contrast, synaptic transmission in IC and $\mathrm{HC}$ is not as precise and neurotransmitter uptake is not that fast. Thus, our data suggest that expression and kinetics of astrocytic inhibitory neurotransmitter transporters are adjusted to the requirements of local circuitry.

\section{Conclusion}

In summary, our results demonstrate the expression of functional GlyT1, GAT-1, and GAT-3 in all IC astrocytes and about half of the $\mathrm{HC}$ astrocytes. In both regions the activity of GATs is stronger compared to the activity of GlyTs. Whereas $I_{\mathrm{Gly}}(\max )$ is comparable in both regions, $I_{\mathrm{GABA}}(\max )$ is much larger in $\mathrm{HC}$ astrocytes. Accordingly, the $I_{\mathrm{GABA}(\max )} / I_{\mathrm{Gly}(\max )}$ ratio is markedly elevated in $\mathrm{HC}$ astrocytes. Furthermore, astrocytic GlyTs and GATs in IC as well as $\mathrm{HC}$ exhibit slower transporter kinetics in comparison to those transporters in LSO astrocytes, thereby reflecting the regionally differing demands for temporal precision of synaptic transmission. Altogether, our results show that astrocytes do not uniformly express inhibitory neurotransmitter transporters, but region specifically adapt to the requirements of local circuitry.

\section{Additional files}

Additional file 1: Figure S1. Basic characterization of $\mathrm{IC}$ and $\mathrm{HC}$ neurons. A: Reconstruction of a single IC and $\mathrm{HC}$ neuron. Dendrite topography of the IC neuron correlated with isofrequency bands (dorsomedial to ventrolateral orientation; $\left.A_{7}\right)$. Basal and apical dendrites from CA1 pyramidal cell extended into stratum oriens $(\mathrm{SO})$ and stratum radiatum $(S R)$, respectively $\left(A_{2}\right)$. B: Neurons were clamped to $E_{\mathrm{H}}=-70 \mathrm{mV}$ and were stepwise hyper- and depolarized from $-150 \mathrm{mV}$ to $+50 \mathrm{mV}$, with $10 \mathrm{mV}$ increments. IC $\left(B_{1}\right)$ and $\mathrm{HC}\left(B_{2}\right)$ neurons expressed voltage-dependent early inward and delayed outward currents. Inset: higher temporal resolution of inward currents. Scale bars: 1 ms. (TIFF $1876 \mathrm{~kb}$ )

Additional file 2: Figure S2. Glycine and GABA induced $R_{\mathrm{M}}$ reduction in $\mathrm{IC}$ and $\mathrm{HC}$ neurons. A: Voltage-clamp protocol including 11 test pulses $\left(t_{0-10}\right)$. B-E: Neurons were clamped to $E_{\mathrm{H}}=-70 \mathrm{mV}$. Focal application of glycine or GABA (1 mM, 10 s; triangles) induced a transient outward current $\left(B_{1}-E_{1}\right)$. Responses to test pulses at $t_{0}, t_{1}, t_{5}$, and $t_{10}\left(B_{2}-E_{2}\right)$ allowed calculation of $R_{\mathrm{M}}$. Upon glycine or GABA application $R_{\mathrm{M}}$ was reduced in IC and $\mathrm{HC}$ neurons $\left(B_{3}-E_{3}\right) . n$ represents the number of recorded cells. Shown are mean values \pm SEM. Significance levels in panels $B_{3}-E_{3}$ were Šidák corrected for three comparisons (see Methods section). (TIFF $2112 \mathrm{~kb}$ )

Additional file 3: Figure S3. Controls for single-cell RT-PCR. Random RNA prepared from brainstem served as positive control (p.c.). For negative control (n.c.) a patch pipette was dipped into ACSF and was placed closely to the surface of the slice without patching a cell. All targeted mRNAs were detected in p.c., whereas the n.c. was free of signals. (TIFF $1434 \mathrm{~kb}$ )

\section{Abbreviations}

AF: Alexa fluor; $E_{H}$ : Holding potential; GABA $A_{A} R$ : GABA A receptor; GAT: GABA transporter; GlyT: Glycine transporter; HC: Hippocampus; IC: Inferior colliculus; $I_{\text {GABA (max): }}$ Maximal GABA-induced current; $I_{\text {GABA: }}$ GABA-induced current;

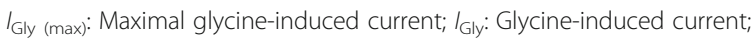
LSO: Lateral superior olive; NMDAR: NMDA receptor; $R_{\mathrm{M}}$ : Membrane resistance; $R_{\mathbf{S}}$ : Series resistance; $R T-P C R$ : Reverse transcription PCR; SOC: Superior olivary complex

Acknowledgements

We thank Jennifer Winkelhoff and Ayse Maraslioglu for excellent technical assistance.

\section{Funding}

This study was supported by the German Research Foundation (DFG Priority Program 1608 "Ultrafast and temporally precise information processing: Normal and dysfunctional hearing", Ste. 2352/2-1), the Nachwuchsring of TU Kaiserslautern, and the University of Milan funding the internship of EG.

\section{Availability of data and materials}

Please contact author for data request.

\section{Authors' contributions}

JS designed experiments and figures. EG, VA, SLW, JB, and SB performed experiments and analyzed data. GS helped to establish single-cell RT-PCR. JS wrote the manuscript. EG, SLW, SB, JH, and GS contributed to the writing. All authors read and approved the final manuscript.

\section{Ethics approval}

Mice were treated in accordance with the German law for conducting animal experiments and the $\mathrm{NIH}$ guidelines for the care and use of laboratory animals.

Consent for publication

Not applicable.

\section{Competing interests}

The authors declare that they have no competing interests.

\section{Publisher's Note}

Springer Nature remains neutral with regard to jurisdictional claims in published maps and institutional affiliations.

\section{Author details}

${ }^{1}$ Animal Physiology Group, Department of Biology, University of Kaiserslautern, Erwin Schroedinger-Strasse 13, D-67663 Kaiserslautern, Germany. ${ }^{2}$ Department of Medical Biotechnology and Translational Medicine, University of Milan, via Vanvitelli 32, I-20129 Milan, Italy. ${ }^{3}$ Pharmacology and Brain Pathology Lab, Humanitas Clinical and Research Center, via Manzoni 56, I-20089 Rozzano, Italy. ${ }^{4}$ Institute of Cellular Neurosciences, Medical Faculty, University of Bonn, Sigmund-Freud-Strasse 25, D-53105 Bonn, Germany.

Received: 16 October 2017 Accepted: 3 January 2018

Published online: 25 January 2018

\section{References}

1. Dumoulin A, Triller A, Dieudonne S. IPSC kinetics at identified GABAergic and mixed GABAergic and glycinergic synapses onto cerebellar Golgi cells. $J$ Neurosci. 2001;21:6045-57.

2. Kotak VC, Korada S, Schwartz IR, Sanes DH. A developmental shift from GABAergic to glycinergic transmission in the central auditory system. J Neurosci. 1998;18:4646-55.

3. Nabekura J, Katsurabayashi S, Kakazu Y, Shibata S, Matsubara A, Jinno S, Mizoguchi Y, Sasaki A, Ishibashi H. Developmental switch from GABA to glycine release in single central synaptic terminals. Nat Neurosci. 2004;7:17-23.

4. Friauf E, Fischer AU, Fuhr MF. Synaptic plasticity in the auditory system: a review. Cell Tissue Res. 2015;361:177-213.

5. Rahman J, Latal AT, Besser S, Hirrlinger J, Hulsmann S. Mixed miniature postsynaptic currents resulting from co-release of glycine and GABA recorded from glycinergic neurons in the neonatal respiratory network. Eur J Neurosci. 2013;37:1229-41.

6. Ishibashi H, Yamaguchi J, Nakahata Y, Nabekura J. Dynamic regulation of glycine-GABA co-transmission at spinal inhibitory synapses by neuronal glutamate transporter. J Physiol. 2013;591:3821-32. 
7. Nerlich J, Rubsamen R, Milenkovic I. Developmental shift of inhibitory transmitter content at a central auditory synapse. Front Cell Neurosci. 2017;11:211.

8. Moore LA, Trussell LO. Co-release of inhibitory neurotransmitters in the mouse auditory midbrain. J Neurosci. 2017;37(39):9453-64.

9. Klausberger T. GABAergic interneurons targeting dendrites of pyramidal cells in the CA1 area of the hippocampus. Eur I Neurosci. 2009;30:947-57.

10. Rombo DM, Ribeiro JA, Sebastiao AM. Hippocampal GABAergic transmission: a new target for adenosine control of excitability. J Neurochem. 2016;139:1056-70

11. Cubelos B, Gimenez C, Zafra F. Localization of the GLYT1 glycine transporter at glutamatergic synapses in the rat brain. Cereb Cortex. 2005;15:448-59.

12. Muller E, Bakkar W, Martina M, Sokolovski A, Wong AY, Legendre P, Bergeron R. Vesicular storage of glycine in glutamatergic terminals in mouse hippocampus. Neuroscience. 2013;242:110-27.

13. Zafra F, Aragon C, Olivares L, Danbolt NC, Gimenez C, Storm-Mathisen J. Glycine transporters are differentially expressed among CNS cells. J Neurosci. 1995;15:3952-69.

14. Zafra F, Gomeza J, Olivares L, Aragon C, Gimenez C. Regional distribution and developmental variation of the glycine transporters GLYT1 and GLYT2 in the rat CNS. Eur J Neurosci. 1995;7:1342-52.

15. Stephan J. Heterogeneous distribution and utilization of inhibitory neurotransmitter transporters. Neurotransmitter. 2015;2:10-14800/nt. 491

16. Borden LA. GABA transporter heterogeneity: pharmacology and cellular localization. Neurochem Int. 1996;29:335-56.

17. Eulenburg V, Gomeza J. Neurotransmitter transporters expressed in glial cells as regulators of synapse function. Brain Res Rev. 2010;63:103-12.

18. Kirischuk S, Heja L, Kardos J, Billups B. Astrocyte sodium signaling and the regulation of neurotransmission. Glia. 2016;64:1655-66.

19. Stephan J, Friauf E. Functional analysis of the inhibitory neurotransmitter transporters GlyT1, GAT-1, and GAT-3 in astrocytes of the lateral superior olive. Glia. 2014;62:1992-2003.

20. Szoke K, Hartel K, Grass D, Hirrlinger PG, Hirrlinger J, Hulsmann S. Glycine transporter 1 expression in the ventral respiratory group is restricted to protoplasmic astrocytes. Brain Res. 2006;1119:182-9.

21. Egawa K, Yamada J, Furukawa T, Yanagawa Y, Fukuda A. Cl(-) homeodynamics in gap junction-coupled astrocytic networks on activation of GABAergic synapses. J Physiol. 2013;591:3901-17.

22. Verkhratsky A, Steinhauser C. Ion channels in glial cells. Brain Res Brain Res Rev. 2000;32:380-412.

23. Muller T, Fritschy JM, Grosche J, Pratt GD, Mohler H, Kettenmann $\mathrm{H}$. Developmental regulation of voltage-gated $\mathrm{K}+$ channel and GABAA receptor expression in Bergmann glial cells. J Neurosci. 1994;14:2503-14.

24. Pastor A, Chvatal A, Sykova E, Kettenmann H. Glycine- and GABA-activated currents in identified glial cells of the developing rat spinal cord slice. Eur J Neurosci. 1995;7:1188-98.

25. Kirchhoff F, Mulhardt C, Pastor A, Becker CM, Kettenmann $\mathrm{H}$. Expression of glycine receptor subunits in glial cells of the rat spinal cord. J Neurochem. 1996;66:1383-90.

26. Hoft S, Griemsmann S, Seifert G, Steinhauser C. Heterogeneity in expression of functional ionotropic glutamate and GABA receptors in astrocytes across brain regions: insights from the thalamus. Philos Trans R Soc Lond Ser B Biol Sci. 2014;369:20130602

27. Casseday JH, Fremouw T, Covey E. The inferior colliculus: a hub for the central auditory system. In: Oertel D, Fay RR, Popper AN, editors. Integrative functions in the mammalian auditory pathway. Berlin: Springer; 2002. p. 238-318.

28. Chandrasekaran L, Xiao Y, Sivaramakrishnan S. Functional architecture of the inferior colliculus revealed with voltage-sensitive dyes. Front Neural Circuits. 2013;7:41.

29. Saint Marie RL, Baker RA. Neurotransmitter-specific uptake and retrograde transport of [3H]glycine from the inferior colliculus by ipsilateral projections of the superior olivary complex and nuclei of the lateral lemniscus. Brain Res. 1990;524:244-53.

30. Moore DR, Kotak VC, Sanes DH. Commissural and lemniscal synaptic input to the gerbil inferior colliculus. J Neurophysiol. 1998;80:2229-36.

31. Choy Buentello D, Bishop DC, Oliver DL. Differential distribution of GABA and glycine terminals in the inferior colliculus of rat and mouse. J Comp Neurol. 2015;523:2683-97.

32. Fyk-Kolodziej BE, Shimano T, Gafoor D, Mirza N, Griffith RD, Gong TW, Holt AG. Dopamine in the auditory brainstem and midbrain: co-localization with amino acid neurotransmitters and gene expression following cochlear trauma. Front Neuroanat. 2015;9:88.
33. Akbar MT, Rattray M, Williams RJ, Chong NW, Meldrum BS. Reduction of GABA and glutamate transporter messenger RNAs in the severe-seizure genetically epilepsy-prone rat. Neuroscience. 1998;85:1235-51.

34. Moritz CP, Eckstein E, Tenzer S, Friauf E. Neuroproteomics in the auditory brainstem: candidate proteins for ultrafast and precise information processing. Mol Cell Neurosci. 2015;64:9-23.

35. Walker MC, Galley PT, Errington ML, Shorvon SD, Jefferys JG. Ascorbate and glutamate release in the rat hippocampus after perforant path stimulation: a "dialysis electrode" study. J Neurochem. 1995;65:725-31.

36. Fleck MW, Henze DA, Barrionuevo G, Palmer AM. Aspartate and glutamate mediate excitatory synaptic transmission in area CA1 of the hippocampus. J Neurosci. 1993;13:3944-55.

37. Kersante F, Rowley SC, Pavlov I, Gutierrez-Mecinas M, Semyanov A, Reul JM, Walker MC, Linthorst AC. A functional role for both -aminobutyric acid (GABA) transporter-1 and GABA transporter-3 in the modulation of extracellular GABA and GABAergic tonic conductances in the rat hippocampus. J Physiol. 2013;591:2429-41.

38. Musante V, Summa M, Cunha RA, Raiteri M, Pittaluga A. Pre-synaptic glycine GlyT1 transporter-NMDA receptor interaction: relevance to NMDA autoreceptor activation in the presence of $\mathrm{Mg} 2+$ ions. J Neurochem. 2011; 117:516-27.

39. Fujita $H$, Sato K, Wen TC, Peng Y, Sakanaka M. Differential expressions of glycine transporter 1 and three glutamate transporter mRNA in the hippocampus of gerbils with transient forebrain ischemia. J Cereb Blood Flow Metab. 1999;19:604-15.

40. Aroeira RI, Sebastiao AM, Valente CA. GlyT1 and GlyT2 in brain astrocytes: expression, distribution and function. Brain Struct Funct. 2014;219:817-30.

41. Augustin V, Bold C, Wadle SL, Langer J, Jabs R, Philippot C, Weingarten DJ, Rose CR, Steinhauser C, Stephan J. Functional anisotropic panglial networks in the lateral superior olive. Glia. 2016:64:1892-911.

42. Kafitz KW, Meier SD, Stephan J, Rose CR. Developmental profile and properties of sulforhodamine 101-labeled glial cells in acute brain slices of rat hippocampus. J Neurosci Methods. 2008;169:84-92.

43. Jurkovicova-Tarabova B, Griesemer D, Pirone A, Sinnegger-Brauns MJ, Striessnig J, Friauf E. Repertoire of high voltage-activated $\mathrm{Ca} 2+$ channels in the lateral superior olive: functional analysis in wild-type, ca(v)1.3(-/-), and ca(v)1.2DHP(-/-) mice. J Neurophysiol. 2012;108:365-79.

44. Stephan J, Haack N, Kafitz KW, Durry S, Koch D, Hochstrate P, Seifert G, Steinhauser C, Rose CR. Kir4.1 channels mediate a depolarization of hippocampal astrocytes under hyperammonemic conditions in situ. Glia. 2012;60:965-78.

45. Shen Z, Qu W, Wang W, Lu Y, Wu Y, Li Z, Hang X, Wang X, Zhao D, Zhang C. MPprimer: a program for reliable multiplex PCR primer design. BMC Bioinformatics. 2010;11:143.

46. Seifert G, Huttmann K, Binder DK, Hartmann C, Wyczynski A, Neusch C, Steinhauser C. Analysis of astroglial $\mathrm{K}+$ channel expression in the developing hippocampus reveals a predominant role of the Kir4.1 subunit. J Neurosci. 2009;29:7474-88.

47. Schindelin J, Arganda-Carreras I, Frise E, Kaynig V, Longair M, Pietzsch T, Preibisch S, Rueden C, Saalfeld S, Schmid B, Tinevez JY, White DJ, Hartenstein V, Eliceiri K, Tomancak P, Cardona A. Fiji: an open-source platform for biological-image analysis. Nat Methods. 2012;9:676-82.

48. Abdi H. In: Salkind N, editor. The Bonferroni and Šidák corrections for multiple comparisons. Thousand Oaks: editor Encyclopedia of Measurement and Statistics Sage Publications; 2007. p. 103-7.

49. Raiteri L, Stigliani S, Usai C, Diaspro A, Paluzzi S, Milanese M, Raiteri M, Bonanno G. Functional expression of release-regulating glycine transporters GLYT1 on GABAergic neurons and GLYT2 on astrocytes in mouse spinal cord. Neurochem Int. 2008:52:103-12.

50. Kraushaar $\mathrm{U}$, Backus KH. Characterization of GABA(a) and glycine receptors in neurons of the developing rat inferior colliculus. Pflugers Arch. 2002;445:279-88.

51. Chattipakorn SC, MCMahon LL. Pharmacological characterization of glycinegated chloride currents recorded in rat hippocampal slices. J Neurophysiol. 2002:87:1515-25.

52. Banks Ml, Pearce RA. Kinetic differences between synaptic and extrasynaptic GABA(a) receptors in CA1 pyramidal cells. J Neurosci. 2000;20:937-48.

53. Jones MV, Westbrook GL. Desensitized states prolong GABAA channel responses to brief agonist pulses. Neuron. 1995;15:181-91.

54. Lagrange AH, Botzolakis EJ, Macdonald RL. Enhanced macroscopic desensitization shapes the response of alpha4 subtype-containing GABAA receptors to synaptic and extrasynaptic GABA. J Physiol. 2007;578:655-76. 
55. Uwechue NM, Marx MC, Chevy Q, Billups B. Activation of glutamate transport evokes rapid glutamine release from perisynaptic astrocytes. J Physiol. 2012;590:2317-31.

56. Zhou M, Schools GP, Kimelberg HK. Development of GLAST(+) astrocytes and NG2(+) glia in rat hippocampus CA1: mature astrocytes are electrophysiologically passive. J Neurophysiol. 2006:95:134-43.

57. Seifert G, Steinhauser C. Heterogeneity and function of hippocampal macroglia. Cell Tissue Res. 2017;4:1-8.

58. Matthias K, Kirchhoff F, Seifert G, Huttmann K, Matyash M, Kettenmann H, Steinhauser C. Segregated expression of AMPA-type glutamate receptors and glutamate transporters defines distinct astrocyte populations in the mouse hippocampus. J Neurosci. 2003;23:1750-8.

59. Muller J, Reyes-Haro D, Pivneva T, Nolte C, Schaette R, Lubke J, Kettenmann $H$. The principal neurons of the medial nucleus of the trapezoid body and NG2(+) glial cells receive coordinated excitatory synaptic input. J Gen Physiol. 2009;134:115-27

60. Reyes-Haro D, Muller J, Boresch M, Pivneva T, Benedetti B, Scheller A, Nolte $\mathrm{C}$, Kettenmann $\mathrm{H}$. Neuron-astrocyte interactions in the medial nucleus of the trapezoid body. J Gen Physiol. 2010;135:583-94.

61. Mezler M, Hornberger W, Mueller R, Schmidt M, Amberg W, Braje W, Ochse $\mathrm{M}$, Schoemaker H, Behl B. Inhibitors of GlyT1 affect glycine transport via discrete binding sites. Mol Pharmacol. 2008;74:1705-15.

62. Utsunomiya-Tate N, Endou $\mathrm{H}$, Kanai Y. Cloning and functional characterization of a system ASC-like Na+-dependent neutral amino acid transporter. J Biol Chem. 1996;271:14883-90.

63. Kanai Y, Hediger MA. The glutamate/neutral amino acid transporter family SLC1: molecular, physiological and pharmacological aspects. Pflugers Arch. 2004;447:469-79.

64. Mackenzie B, Erickson JD. Sodium-coupled neutral amino acid (system N/a) transporters of the SLC38 gene family. Pflugers Arch. 2004;447:784-95.

65. Broer A, Albers A, Setiawan I, Edwards RH, Chaudhry FA, Lang F, Wagner CA, Broer $\mathrm{S}$. Regulation of the glutamine transporter SN1 by extracellular $\mathrm{pH}$ and intracellular sodium ions. J Physiol. 2002;539:3-14.

66. Schools GP, Zhou M, Kimelberg HK. Development of gap junctions in hippocampal astrocytes: evidence that whole cell electrophysiological phenotype is an intrinsic property of the individual cell. J Neurophysiol. 2006;96:1383-92.

67. Langer J, Stephan J, Theis M, Rose CR. Gap junctions mediate intercellular spread of sodium between hippocampal astrocytes in situ. Glia. 2012;60:239-52

68. Wallraff A, Kohling R, Heinemann U, Theis M, Willecke K, Steinhauser C. The impact of astrocytic gap junctional coupling on potassium buffering in the hippocampus. J Neurosci. 2006;26:5438-47.

69. D'Ambrosio R, Wenzel J, Schwartzkroin PA, McKhann GM 2nd, Janigro D. Functional specialization and topographic segregation of hippocampal astrocytes. J Neurosci. 1998;18:4425-38.

70. Xu G, Wang W, Kimelberg HK, Zhou M. Electrical coupling of astrocytes in rat hippocampal slices under physiological and simulated ischemic conditions. Glia. 2010:58:481-93.

71. Wang J, Li Z, Feng M, Ren K, Shen G, Zhao C, Jin X, Jiang K. Opening of astrocytic mitochondrial ATP-sensitive potassium channels upregulates electrical coupling between hippocampal astrocytes in rat brain slices. PLoS One. 2013;8:e56605.

72. Meme W, Vandecasteele M, Giaume C, Venance L. Electrical coupling between hippocampal astrocytes in rat brain slices. Neurosci Res. 2009;63:236-43.

73. Heja L, Barabas P, Nyitrai G, Kekesi KA, Lasztoczi B, Toke O, Tarkanyi G, Madsen K, Schousboe A, Dobolyi A, Palkovits M, Kardos J. Glutamate uptake triggers transporter-mediated GABA release from astrocytes. PLoS One. 2009;4:e7153.

74. Milanese M, Romei C, Usai C, Oliveri M, Raiteri L. A new function for glycine GlyT2 transporters: stimulation of gamma-aminobutyric acid release from cerebellar nerve terminals through GAT1 transporter reversal and ca(2 +)-dependent anion channels. J Neurosci Res. 2014;92:398-408.

75. Barakat L, Bordey A. GAT-1 and reversible GABA transport in Bergmann glia in slices. J Neurophysiol. 2002;88:1407-19.

76. Biedermann B, Bringmann A, Reichenbach A. High-affinity GABA uptake in retinal glial (Muller) cells of the guinea pig: electrophysiological characterization, immunohistochemical localization, and modeling of efficiency. Glia. 2002;39:217-28.

77. Pirttimaki T, Parri HR, Crunelli V. Astrocytic GABA transporter GAT-1 dysfunction in experimental absence seizures. J Physiol. 2013;591:823-33.

78. Vitellaro-Zuccarello L, Calvaresi N, De Biasi S. Expression of GABA transporters, GAT-1 and GAT-3, in the cerebral cortex and thalamus of the rat during postnatal development. Cell Tissue Res. 2003;313:245-57.
79. Kinney GA, Spain WJ. Synaptically evoked GABA transporter currents in neocortical glia. J Neurophysiol. 2002:88:2899-908.

80. Melone M, Ciappelloni S, Conti F. Plasma membrane transporters GAT-1 and GAT-3 contribute to heterogeneity of GABAergic synapses in neocortex. Front Neuroanat. 2014;8:72.

81. Kirischuk S, Parpura V, Verkhratsky A. Sodium dynamics: another key to astroglial excitability? Trends Neurosci. 2012;35:497-506.

82. Papke D, Gonzalez-Gutierrez G, Grosman C. Desensitization of neurotransmitter-gated ion channels during high-frequency stimulation: a comparative study of Cys-loop, AMPA and purinergic receptors. J Physiol. 2011:589:1571-85.

83. Zhou M, Xu G, Xie M, Zhang X, Schools GP, Ma L, Kimelberg HK, Chen H. TWIK-1 and TREK-1 are potassium channels contributing significantly to astrocyte passive conductance in rat hippocampal slices. J Neurosci. 2009; 29:8551-64.

84. Cai G, Salonikidis PS, Fei J, Schwarz W, Schulein R, Reutter W, Fan H. The role of $\mathrm{N}$-glycosylation in the stability, trafficking and GABA-uptake of GABA-transporter 1. Terminal N-glycans facilitate efficient GABA-uptake activity of the GABA transporter. FEBS J. 2005;272:1625-38.

85. Lopez E, Lee-Rivera I, Lopez-Colome AM. Characteristics and regulation of glycine transport in Bergmann glia. Neurochem Res. 2005;30:1567-77.

86. Olivares L, Aragón C, Giménez C, Zafra F. The role ofN-Glycosylation in the targeting and activity of the GLYT1 Glycine transporter. J Biol Chem. 1995; 270:9437-42.

87. Gadea A, Lopez-Colome AM. Glial transporters for glutamate, glycine, and GABA III. Glycine transporters. J Neurosci Res. 2001;64:218-22.

88. Gadea A, Lopez-Colome AM. Glial transporters for glutamate, glycine, and GABA: II. GABA transporters. J Neurosci Res. 2001;63:461-8.

89. Eulenburg V, Armsen W, Betz H, Gomeza J. Glycine transporters: essential regulators of neurotransmission. Trends Biochem Sci. 2005;30:325-33.

90. Tollin DJ. The lateral superior olive: a functional role in sound source localization. Neuroscientist. 2003;9:127-43.

91. Kandler K, Clause A, Noh J. Tonotopic reorganization of developing auditory brainstem circuits. Nat Neurosci. 2009;12:711-7.

92. Kramer F, Griesemer D, Bakker D, Brill S, Franke J, Frotscher E, Friauf E. Inhibitory glycinergic neurotransmission in the mammalian auditory brainstem upon prolonged stimulation: short-term plasticity and synaptic reliability. Front Neural Circuits. 2014;8:14.

93. Krachan EG, Fischer AU, Franke J, Friauf E. Synaptic reliability and temporal precision are achieved via high quantal content and effective replenishment: auditory brainstem versus hippocampus. J Physiol. 2017;595:839-64.

\section{Submit your next manuscript to BioMed Central and we will help you at every step:}

- We accept pre-submission inquiries

- Our selector tool helps you to find the most relevant journal

- We provide round the clock customer support

- Convenient online submission

- Thorough peer review

- Inclusion in PubMed and all major indexing services

- Maximum visibility for your research

Submit your manuscript at www.biomedcentral.com/submit

) BioMed Central 